\title{
Kinetic regimes and limiting cases of gas uptake and heterogeneous reactions in atmospheric aerosols and clouds: a general classification scheme
}

\author{
T. Berkemeier ${ }^{1,2,3}$, A. J. Huisman ${ }^{2, *}$, M. Ammann ${ }^{4}$, M. Shiraiwa ${ }^{3,5}$, T. Koop ${ }^{1}$, and U. Pöschl ${ }^{3}$ \\ ${ }^{1}$ Faculty of Chemistry, Bielefeld University, Bielefeld, Germany \\ ${ }^{2}$ Institute for Atmospheric and Climate Science, ETH Zürich, Zürich, Switzerland \\ ${ }^{3}$ Multiphase Chemistry Department, Max Planck Institute for Chemistry, Mainz, Germany \\ ${ }^{4}$ Laboratory of Radiochemistry and Environmental Chemistry, Paul Scherrer Institute, Villigen, Switzerland \\ ${ }^{5}$ Division of Chemistry and Chemical Engineering, California Institute of Technology, Pasadena, California, USA \\ *now at: Department of Chemistry, Union College, Schenectady, NY, USA
}

Correspondence to: A. J. Huisman (huismana@union.edu)

Received: 30 November 2012 - Published in Atmos. Chem. Phys. Discuss.: 9 January 2013

Revised: 17 May 2013 - Accepted: 30 May 2013 - Published: 15 July 2013

\begin{abstract}
Heterogeneous reactions are important to atmospheric chemistry and are therefore an area of intense research. In multiphase systems such as aerosols and clouds, chemical reactions are usually strongly coupled to a complex sequence of mass transport processes and results are often not easy to interpret.

Here we present a systematic classification scheme for gas uptake by aerosol or cloud particles which distinguishes two major regimes: a reaction-diffusion regime and a mass transfer regime. Each of these regimes includes four distinct limiting cases, characterised by a dominant reaction location (surface or bulk) and a single rate-limiting process: chemical reaction, bulk diffusion, gas-phase diffusion or mass accommodation.

The conceptual framework enables efficient comparison of different studies and reaction systems, going beyond the scope of previous classification schemes by explicitly resolving interfacial transport processes and surface reactions limited by mass transfer from the gas phase. The use of kinetic multi-layer models instead of resistor model approaches increases the flexibility and enables a broader treatment of the subject, including cases which do not fit into the strict limiting cases typical of most resistor model formulations. The relative importance of different kinetic parameters such as diffusion, reaction rate and accommodation coefficients in
\end{abstract}

this system is evaluated by a quantitative global sensitivity analysis. We outline the characteristic features of each limiting case and discuss the potential relevance of different regimes and limiting cases for various reaction systems. In particular, the classification scheme is applied to three different datasets for the benchmark system of oleic acid reacting with ozone in order to demonstrate utility and highlight potential issues. In light of these results, future directions of research needed to elucidate the multiphase chemical kinetics in this and other reaction systems are discussed.

\section{Introduction}

Tropospheric aerosols are composed of organic and inorganic substances originating from direct emission of particles and from condensation of gas-phase species (Kanakidou et al., 2005; Pöschl, 2005; Hallquist et al., 2009; Ziemann and Atkinson, 2012). Aerosols are climate forcers (Streets et al., 2004; Yu et al., 2006; IPCC, 2007; Stevens et al., 2009; Carslaw et al., 2010; Mahowald et. al., 2011) and are implicated in human health effects (Bates, 1993; Jakab et al., 1995; McConnell et al., 2002; Nel, 2005; Heal et al., 2012; Shiraiwa et al., 2012d) as well as other undesirable phenomena 
such as reduced visibility in urban and rural areas. At this time, the physical and chemical properties of aerosols are still poorly understood and despite extensive experimental and modelling efforts, many of the processes central to heterogeneous chemical processing of aerosols remain unclear (Kolb et al., 2010).

Most previous studies of the gas uptake into aerosol particles have used "resistor" models which account for physical and chemical processes for a single or at most a few physical domains within the aerosol particle by analogy to electrical circuits (an overview of resistor models in the canonical system of oleic acid-ozone heterogeneous reaction is given in Zahardis and Petrucci, 2007). Such models allow analytical expressions to be derived for uptake of trace gases or loss of condensed phase material in simplified, limiting cases. These analytical expressions can be used to calculate the underlying kinetic parameters such as reaction rate coefficients or the accommodation coefficient (which are applicable to a reaction system under any conditions) or the trace gas uptake coefficient $\gamma$ (which is specific to the experimental conditions at which it was measured). Using this sort of framework has been fruitful in the past for a wide range of gas/particle processes, and was particularly successful in assessing key heterogeneous interactions of relevance to stratospheric ozone depletion (Hanson et al., 1994). Analysis based on limiting cases has found widespread acceptance and also forms the basis for the recent evaluations by the IUPAC Subcommittee for Gas Kinetic Data Evaluation (Crowley et al., 2010). Because a wide variety of processes are important to multiphase chemistry, it is less well understood than pure gasphase chemistry (e.g. Abbatt et al., 2012) and new methods are needed to facilitate analysis and discussion.

Recently developed depth-resolved models for single particles or thin films that focus on chemistry, such as KM-SUB (Shiraiwa et al., 2010), and water diffusion, such as the ETH Diffusion Model (Zobrist et al., 2011), allow a more complete consideration of the time- and depth-resolved chemical and physical behaviour of aerosol particles, leading to a better understanding of these reaction systems. Shiraiwa et al. (2011a) have shown that resistor models are not sufficient for systems in which the bulk material is radially inhomogeneous in concentration owing to, e.g. diffusion limitations.

Due to the complexity of numerical models such as these, it is often unclear which process is most important to model outputs. Sensitivity analysis provides a simple means of identifying the model parameters which most strongly influence the results (and thus are related to the rate-limiting process). Although many previous studies have employed a local approach, advanced computational tools exist to systematically calculate sensitivity coefficients and take into account higher order parameter effects (the "global methods" in Saltelli et al., 2008). As reviewed in Cariboni et al. (2007), global sensitivity methods have been applied to fields such as ecological modelling, and in atmospheric science advanced sensitivity methods have been applied to models of single gas- phase chemical reactions (e.g. Dunker, 1984) and regional ozone formation (Martien and Harley, 2006). However, to the authors' knowledge this type of sensitivity analysis has not been applied previously to a depth-resolved or resistor-style model of the physicochemical behaviour of single aerosol particles.

Kinetic regimes and limiting cases allow classification of system behaviour for analysis and comparison of model outputs with experimental results. In this work, we propose an enhanced set of limiting cases which can be used for conceptual discussion and analysis along with a systematic, numerically-based method for assigning a limiting case to a reaction system. This classification is compared with the outcome of a global sensitivity analysis to ensure that the system behaviour is consistent with the assignment. The classification system proposed here is broadly applicable and standardized, so that it is portable across many systems. This taxonomy will be useful as a common ground for discussion of heterogeneous chemical processes and as a tool for analysis.

\section{Conceptual framework}

\subsection{Representation of aerosol reaction systems and definitions}

Following the terminology of Pöschl et al. (2007) (the "PRA framework"), we will discuss the reaction of a trace gas species X and a condensed-phase substrate Y. These compounds are assumed to react in a single step, second-order reaction in either (i) a single bulk layer or (ii) between a quasistatic surface layer of $\mathrm{Y}$ and a sorption layer of $\mathrm{X}$. The domains of the gas and condensed phase discussed here are illustrated schematically in Fig. 1 along with the principle mass transport and reaction processes.

In this paper we reserve the term limiting case for a system which is governed by a single, clearly defined rate-limiting process. Examples of limiting cases are systems which are limited solely by slow chemical reaction, or by slow diffusion of reactants $\mathrm{X}$ and $\mathrm{Y}$. We reserve the term kinetic regime for a system which is governed by a few (often only one or two) clearly defined rate-limiting processes. For example, systems which exhibit reaction and/or bulk diffusion limitation fall into a single kinetic regime. Referencing the concepts of reacto-diffusive length and flux (Schwartz and Freiberg, 1981; Hanson et al., 1994; Pöschl et al., 2007), we term this important example the reaction-diffusion regime.

\subsection{Derivation of limiting cases and kinetic regimes}

The cases of limiting behaviour presented here arise from three properties that are fundamental to every aerosol reactive system in which a gas $\mathrm{X}$ reacts with condensed phase $\mathrm{Y}$ : 


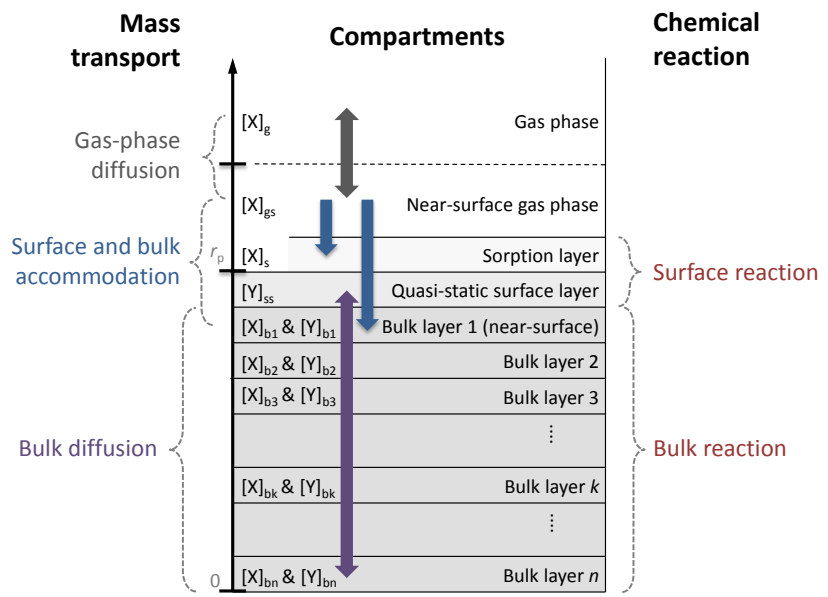

Fig. 1. Processes and compartments discussed in this paper (adapted from Shiraiwa et al., 2010), assuming a system which is either planar or spherically symmetric. Key processes are highlighted. Diffusion of gaseous trace gas $\mathrm{X}$ is assumed to influence the near surface gas-phase concentration $[\mathrm{X}]_{\mathrm{gs}}$ within one mean free path $\lambda_{\mathrm{X}}$ of the particle surface $\left(r_{\mathrm{p}}\right)$. Following Pöschl et al. (2007), surface accommodation denotes the mass flux of $\mathrm{X}$ from the near-surface gas phase to the particle surface, whereas bulk accommodation also includes the subsequent transport into the near-surface bulk. Surface reaction occurs within or between the sorption layer and the quasi-static surface layer consisting of bulk material Y. Reaction and diffusion can take place in $n$ individually resolved bulk layers. All symbols are defined in Table A1.

i. the reaction location, as assessed by the Surface to Total Loss rate Ratio (STLR)

ii. the supply of reactive gas, as assessed by the Saturation Ratio (SR)

iii. the heterogeneity of the system with respect to depth above and below the surface, as assessed by the Mixing Parameter (MP).

Each of the three quantities (STLR, SR, MP) is formulated as a dimensionless parameter ranging from 0 to 1 to allow comparison against a common set of criteria which are not linked to any specific chemical reaction.

Every unique combination of extreme behaviour in the three classification properties leads to a limiting case. This can be visualized in three dimensions as a cube in which each dimension corresponds to one of the classification properties, as shown in Fig. 2. Since all possible cases of kinetic behaviour form the interior of the cube and the faces describe extreme behaviour in one of the classification properties, the eight limiting cases can be depicted as a small volume at each of the vertices, touching three faces each. The eight cases obtained in this way are limited by a single process each and are clearly distinct since they differ in at least one fundamental classification property.

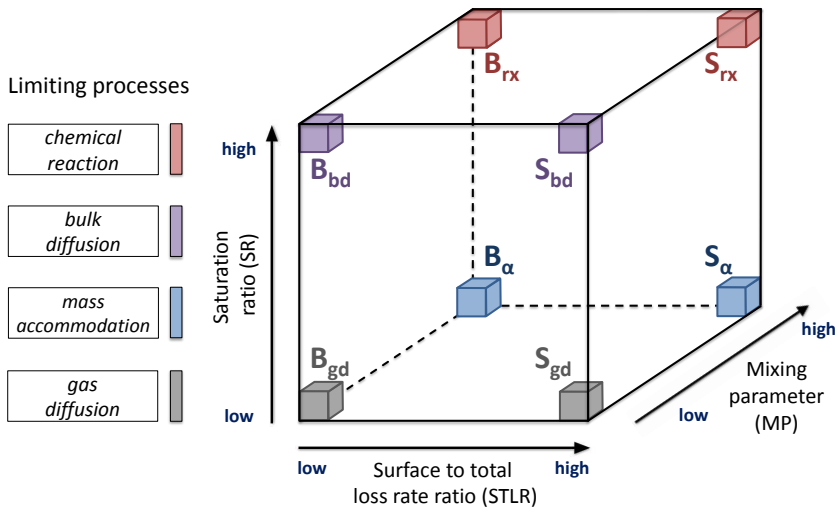

Fig. 2. Kinetic cube: the eight limiting cases can be depicted as the vertices of a cube in which every direction refers to a classification criterion (STLR, SR, MP). They are classified into four types of limiting behaviour: limitation by chemical reaction, bulk diffusion, mass accommodation (including surface and bulk accommodation) and gas diffusion.

To facilitate discussion, we introduce a compact symbolic representation for each limiting case which is used in Fig. 2 and throughout this manuscript. The reaction location is indicated by a central "S" or "B" for surface and bulk, respectively, and a subscript indicates the process which limits reactive uptake. The possible subscripts are: "rx" to indicate chemical reaction; "bd" to indicate bulk diffusion; " $\alpha$ " to indicate accommodation; "gd" to indicate gas-phase diffusion. This framework thus distinguishes four different types of limitation, which are colour-coded in Fig. 2.

A particular strength of numerical modelling (either depthresolved models or numerically solved resistor models) is the ability to work in the "gray area" between well-defined limiting cases. The framework proposed here is compliant with systems in which one or two classification parameters do not exhibit extreme behaviour: these fall into the kinetic regimes defined above. In order to illustrate the concept of a kinetic regime, a few of the many possible regimes are shown in Fig. 3. A straightforward way to generate a regime is to connect the volume which represents two limiting cases to form a volume, which also contains the additional space between the limiting cases and towards the centre of the cube. The resulting regime includes the behaviour of both limiting cases and all systems with classification parameters located in the additional volume. A kinetic regime is thus much broader in its definition than a limiting case. This is depicted in Fig. 3b, where surface and bulk reaction limiting cases with the same limiting process (boxes of the same colour) are connected. We name the four resulting regimes for the process which limits the reactive loss of Y: the reaction, bulk diffusion, gas diffusion and accommodation regimes.

Another possibility is shown in Fig. 3b, where the reaction and bulk diffusion regimes are linked to form a reaction-diffusion regime. This reaction-diffusion regime 
(a)

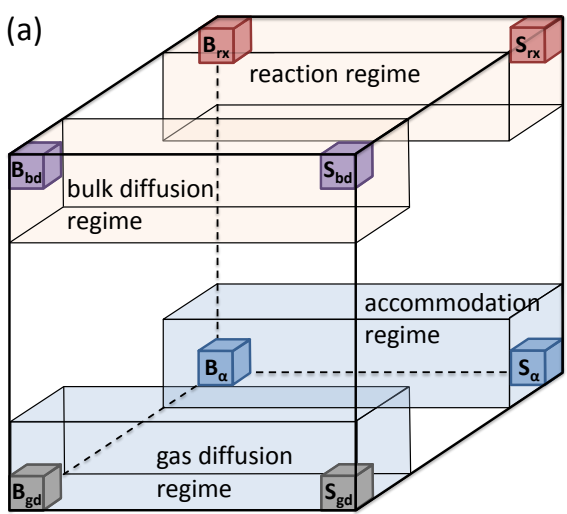

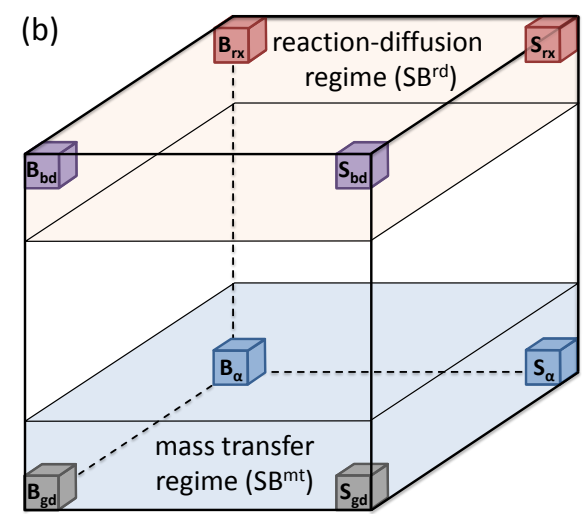

Fig. 3. Visualization of regimes as volumes of the kinetic cube in Fig. 2. (a) shows regimes resulting from the connection of each surface and bulk case. Regime names indicate the limiting process (the reaction regime is limited by reaction rate coefficients etc.). (b) shows a combination of the regimes in (a) in which the reaction and bulk diffusion regimes together form the reaction-diffusion regime and the accommodation and gas diffusion regimes together form the mass transfer regime.

thus includes systems which are limited by reaction, bulk diffusion, or both processes in situations where they are tightly coupled (reacto-diffusive limitation). We note that the term "reacto-diffusive" traditionally referred to bulk reaction systems with a strong gradient in $\mathrm{X}$ and no gradient in Y (see e.g. Danckwerts, 1951; Schwartz, 1986; Hanson et al., 1994; Davidovits et al., 1995; Ravishankara, 1997; Kolb et al., 1998; Ravishankara and Longfellow, 1999; Davidovits et al., 2006; Pöschl et al., 2007; Kolb et al., 2010). Throughout this paper we will refer to this case as the "traditional reacto-diffusive case". However, our definition of the reaction-diffusion regime also includes cases with gradients in the bulk material Y in both bulk and surface reaction systems. In these systems, a reacto-diffusive steady state forms when both the diffusion of reactants towards the reaction site and the actual chemical reaction are limiting trace gas uptake. The complementary regime is a combination of the accommodation and gas diffusion regimes, which we will refer to as the "mass transfer"-limited regime as both are related to the transfer of X from the gas to the particle phase.

To facilitate discussion of regimes, we introduce additional symbols which are similar to that of the limiting cases defined above. Again, "S" and "B" are used to indicate reaction location, and superscripts are used to avoid confusion in identifying the rate-limiting processes. Additional possible superscripts are "rd" to indicate reaction-diffusion limitation and " $m t$ " to indicate mass transfer limitation. In case the surface contribution parameter STLR does not show extreme behaviour, a regime can still be specified if the other classification parameters are consistent. For example, if STLR is $\sim 0.5$ but saturation ratio $\mathrm{SR}$ is high, we can assign the behaviour as $\mathrm{SB}^{\text {rd }}$, where the central symbol is "SB" to indicate that both surface and bulk reactions contribute. The traditional reacto-diffusive case as defined above (bulk reaction, gradient only in $\mathrm{X}$ ) will be denoted as $\mathrm{B}_{\text {trad }}^{\text {rd }}$ to distinguish it from the broad manifold of possible behaviours encom- passed in our reaction-diffusion regime, $\mathrm{SB}^{\mathrm{rd}}$. In addition to the regimes already presented here, a variety of other regimes are possible; a few of them are documented in Appendix B.

\subsection{Classification scheme and criteria}

Here we present a sequential method to apply the three parameters defined above to unambiguously determine the limiting case of a reacting aerosol particle. These classification parameters will be described in detail in Sects. 2.3.1-2.3.3. An overview of the process is given in Fig. 4 and the resulting limiting cases and kinetic regimes are summarised in Table 1.

In the following sections, each of the three classification parameters is framed as a question to provide insight into the processes which most strongly influence the gas uptake. It is important to note that multiple functional forms of SR and MP exist; one of each is chosen for use depending on the result of the previous classification parameters. For example, the mixing parameter for a reaction which occurs primarily at the surface should not reflect a depthwise gradient in bulk X.

A conceptual discussion of the physical and chemical behaviour of each limiting case is possible without appealing to any specific numerical model, but the process of calculating parameter values to assign a limiting case for some experimental data requires the output of a depth-resolved model. The criteria are constructed assuming that model outputs are discretized into spherical or planar layers for droplets and films, respectively, as such discretized treatment is common in current-generation models (see Fig. 1).

\subsubsection{Criterion 1: surface to total loss rate ratio (STLR)}

This term answers the question: What is the dominant reaction location, surface or bulk? The surface to total loss rate ratio (STLR) is used to determine which locality, if any, dominates the chemical loss of Y. The loss rates at the surface, $L_{\mathrm{S}}$ 


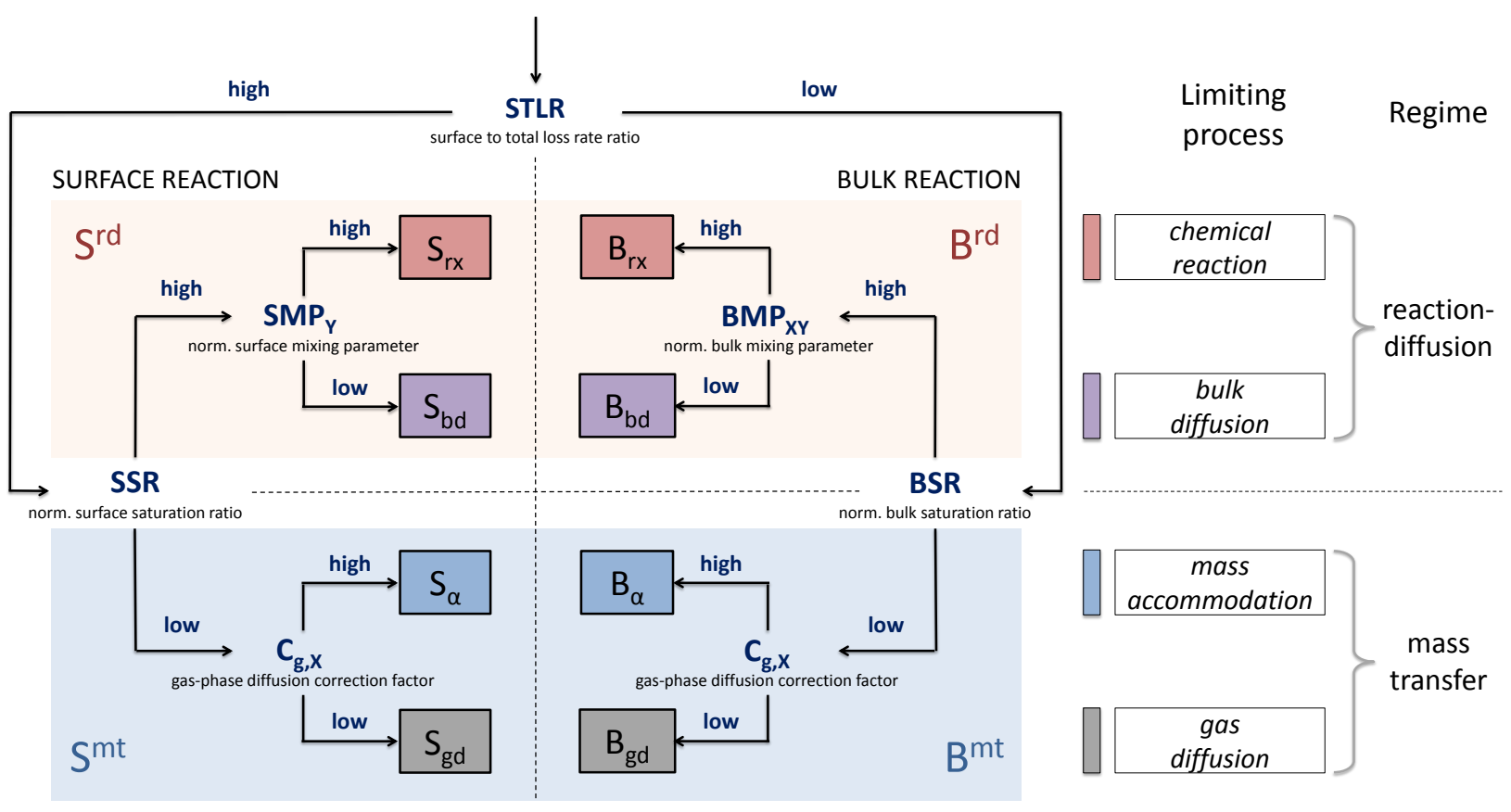

Fig. 4. Classification scheme for distinction of limiting cases. The decision process proceeds in three steps according to Sect. 2. Surface dominated cases (left half) and bulk dominated cases (right half) are distinguished in the first step by comparing the surface to the total loss rate (STLR). Reaction-diffusion systems (top half) and mass transfer-limited systems (bottom half) are distinguished in the second step by evaluating the saturation ratio (SR). In the last step mixing of the components is considered. Note that even though the scheme appears to be symmetric for surface and bulk reaction systems, the classification parameters differ between the left and the right side of the diagram in the second and third decision step. The reaction-diffusion and mass transfer regimes are indicated by large shaded boxes and the respective regime symbols are given in their outward corners.

Table 1. The principle regimes and limiting cases, defined in terms of two and three classification parameters, respectively. The classification properties are the surface to total loss rate ratio (STLR), the saturation ratio(s) (SR) and the mixing parameter(s) (MP). When more than one expression for a classification property is possible (SR/MP), the expression is listed along with a rough criterion.

\begin{tabular}{|c|c|c|c|c|c|}
\hline STLR & SR & Regime & MP & Limiting Case & Description \\
\hline$\approx 1$ & $\mathrm{SSR} \approx 1$ & $\mathrm{~S}^{\mathrm{rd}}$ & $\begin{array}{l}\mathrm{SMP}_{\mathrm{Y}} \approx 1 \\
\mathrm{SMP}_{\mathrm{Y}} \approx 0\end{array}$ & $\begin{array}{l}\mathrm{S}_{\mathrm{rx}} \\
\mathrm{S}_{\mathrm{bd}}\end{array}$ & $\begin{array}{l}\text { Surface reaction limited by chemical reaction } \\
\text { Surface reaction limited by bulk diffusion of } \\
\text { condensed reactant } Y\end{array}$ \\
\hline$\approx 1$ & $\mathrm{SSR} \approx 0$ & $\mathrm{~S}^{\mathrm{mt}}$ & $\begin{array}{l}C_{\mathrm{g}, \mathrm{X}} \approx 1 \\
C_{\mathrm{g}, \mathrm{X}} \approx 0\end{array}$ & $\begin{array}{l}\mathrm{S}_{\alpha} \\
\mathrm{S}_{\mathrm{gd}}\end{array}$ & $\begin{array}{l}\text { Surface reaction limited by surface accommodation of } X \\
\text { Surface reaction limited by gas-phase diffusion of } X\end{array}$ \\
\hline$\approx 0$ & $\mathrm{BSR} \approx 1$ & $\mathrm{~B}^{\mathrm{rd}}$ & $\begin{array}{l}\mathrm{BMP}_{\mathrm{XY}} \approx 1 \\
\mathrm{BMP}_{\mathrm{XY}} \approx 0\end{array}$ & $\begin{array}{l}\mathrm{B}_{\mathrm{rx}} \\
\mathrm{B}_{\mathrm{bd}}\end{array}$ & $\begin{array}{l}\text { Bulk reaction limited by chemical reaction } \\
\text { Bulk reaction limited by bulk diffusion of volatile reactant } \\
\mathrm{X} \text { and condensed reactant } \mathrm{Y}\end{array}$ \\
\hline$\approx 0$ & $\mathrm{BSR} \approx 0$ & $\mathrm{~B}^{\mathrm{mt}}$ & $\begin{array}{l}C_{\mathrm{g}, \mathrm{X}} \approx 1 \\
C_{\mathrm{g}, \mathrm{X}} \approx 0\end{array}$ & $\begin{array}{l}\mathrm{B}_{\alpha} \\
\mathrm{B}_{\mathrm{gd}}\end{array}$ & $\begin{array}{l}\text { Bulk reaction limited by bulk accommodation of } X \\
\text { Bulk reaction limited by gas-phase diffusion of } X\end{array}$ \\
\hline
\end{tabular}


and in the $k$-th bulk layer, $L_{\mathrm{b} k}$, can be calculated as follows:

$L_{\mathrm{S}}=k_{\mathrm{SLR}}[\mathrm{X}]_{\mathrm{S}}[\mathrm{Y}]_{\mathrm{ss}}$

$L_{\mathrm{b} k}=k_{\mathrm{BR}}[\mathrm{X}]_{\mathrm{b} k}[\mathrm{Y}]_{\mathrm{b} k}$

Here $k_{\mathrm{SLR}}$ and $k_{\mathrm{BR}}$ are the second-order reaction rate coefficients in the bulk and in the surface layer, respectively, [X] and $[\mathrm{Y}]$ are the concentrations of the reactants and the subscripts s, ss, and $b k$ indicate the sorption layer, the quasistatic surface layer, and the $k$-th bulk layer, respectively (see also Fig. 1 above). For a total of $n$ bulk layers, the STLR can then be calculated as:

$\mathrm{STLR} \equiv \frac{L_{\mathrm{S}}}{L_{\mathrm{s}}+\sum_{k=1}^{n} L_{k}}$

In Fig. 4, the STLR decision distinguishes the surface (left half) from the bulk reaction cases (right half). The numerical interpretation of STLR is

1. As STLR approaches zero, the reaction occurs primarily in the bulk.

2. As STLR approaches unity, the reaction occurs primarily at the surface.

\subsubsection{Criterion 2: saturation ratio (SR)}

This term answers the question: Is the supply of external gas limiting the reaction rate? This criterion classifies particles by the abundance of $\mathrm{X}$ at the surface or in the first bulk layer, and is thus used as a proxy for the balance between supply of X (from the gas phase) and loss of X (by desorption, surface reaction, bulk reaction, and diffusion into the bulk) in those locations. In Fig. 4, this decision step distinguishes the reaction-diffusion regime with high $\mathrm{SR}$ (top, $\mathrm{SB}^{\text {rd }}$ regime) from the mass transfer regime with low SR (bottom, $\mathrm{SB}^{\mathrm{mt}}$ regime). In both the surface and the bulk case detailed below, the actual concentration of $\mathrm{X}$ in the locale where reaction occurs is compared to the saturation value of $\mathrm{X}$ which would be achieved in the absence of reacto-diffusive loss, leading to a direct determination of which regime a system expresses, reaction-diffusion limitation or mass transfer limitation.

\section{SR in surface-reaction dominated cases}

In cases where surface reaction dominates $(\mathrm{STLR} \approx 1)$, the $\mathrm{SR}$ is calculated as the Surface Saturation Ratio (SSR). With this parameter, the surface concentration of $\mathrm{X}$ is compared to the surface saturation concentration $[X]_{\mathrm{s} \text {,sat }}$. In the absence of reaction or diffusion into the bulk, the saturation concentration of $\mathrm{X}$ at the surface is determined by the rates of adsorption and desorption $k_{\mathrm{a}}$ and $k_{\mathrm{d}}$ :

$[\mathrm{X}]_{\mathrm{s}, \mathrm{sat}}=\frac{k_{\mathrm{a}}}{k_{\mathrm{d}}} \cdot[\mathrm{X}]_{\mathrm{g}}=K_{\mathrm{ads}, \mathrm{X}} \cdot[\mathrm{X}]_{\mathrm{g}}$
Here $[\mathrm{X}]_{\mathrm{g}}$ is the near-surface gas-phase concentration of $\mathrm{X}$ and $K_{\mathrm{ads}, \mathrm{X}}$ is a Langmuir-type adsorption equilibrium constant (see Fig. 1). The SSR is defined as the ratio of $X$ to its saturation concentration at adsorption equilibrium:

$\mathrm{SSR}=\frac{\theta_{\mathrm{s}, \mathrm{X}}}{\theta_{\mathrm{s}, \mathrm{sat}, \mathrm{X}}}=\frac{[\mathrm{X}]_{\mathrm{s}}}{[\mathrm{X}]_{\mathrm{s}, \mathrm{sat}}}$

where $\theta_{\mathrm{S}, \mathrm{X}}$ is surface coverage as defined in Pöschl et al. (2007) and $\theta_{\mathrm{s}, \mathrm{sat}, \mathrm{X}}$ (not to be confused with $\theta_{\mathrm{s}, \max }=1$ ) is the saturation coverage achievable at the equilibrium surface concentration defined in Eq. (4).

\section{SR in bulk-reaction dominated cases}

In cases where bulk reaction dominates (STLR $\approx 0$ ), the $\mathrm{SR}$ is calculated as the Bulk Saturation Ratio (BSR). In this parameter, the concentration of $\mathrm{X}$ in the first subsurface bulk layer $\left([\mathrm{X}]_{\mathrm{b} 1}\right)$ is compared to the saturation concentration $\left([\mathrm{X}]_{\mathrm{b}, \mathrm{sat}}\right)$ achievable under equilibrium conditions in the absence of reacto-diffusive loss:

$\mathrm{BSR}=\frac{[\mathrm{X}]_{\mathrm{b} 1}}{[\mathrm{X}]_{\mathrm{b}, \mathrm{sat}}}$

Here we suggest that $[\mathrm{X}]_{\mathrm{b} \text {,sat }}$ should be defined in terms of the Henry's law equilibrium constant and the gas-phase concentration $[\mathrm{X}]_{\mathrm{g}}$. The numerical interpretation common to both representations of the saturation ratio $\mathrm{SR}$ is:

1. As SR approaches zero, the system is starved of $X$ and is mass transfer-limited ( $\mathrm{SB}^{\mathrm{mt}}$ regime).

2. As SR approaches unity, the system is adequately supplied with $\mathrm{X}$ and experiences reaction-diffusion limitation $\left(\mathrm{SB}^{\mathrm{rd}}\right.$ regime).

\subsubsection{Criterion 3: mixing parameters (MP)}

This term answers the question: What is limiting the reaction rate: mixing or chemistry? Much of the additional information in depth-resolved models is included in the parameter set which represents the spatial heterogeneity in the system. In the case of a surface reaction, a slow diffusion of $\mathrm{Y}$ to the surface may hinder the reaction, while in the bulk, reaction speed may be limited by the diffusion of $\mathrm{X}$ and possibly the diffusion of Y. In mass transfer-limited systems, only mixing in the gas phase has to be considered. Thus, three different mixing parameters (MP) are used to assess mixing in reacting particles: (i) The surface mixing parameter of $\mathrm{Y}, \mathrm{SMP}_{\mathrm{Y}}$, for reaction-diffusion-limited surface reaction systems $\left(\mathrm{S}^{\mathrm{rd}}\right)$; (ii) the bulk mixing parameter of $\mathrm{X}$ and $\mathrm{Y}, \mathrm{BMP}_{\mathrm{XY}}$, for reaction-diffusion-limited bulk reaction systems $\left(\mathrm{B}^{\text {rd }}\right)$ and (iii) the gas-phase diffusion correction factor, $\mathrm{C}_{\mathrm{g}, \mathrm{X}}$, for mass transfer-limited systems $\left(\mathrm{SB}^{\mathrm{mt}}\right)$. In Fig. 4, this classification step divides the reaction-diffusion and mass transfer-limited regimes each into well-mixed cases (top half) and cases which are limited by bulk or gas-phase gradients (bottom half). 


\section{MP in surface reaction-diffusion-limited systems}

In surface reaction-diffusion limited systems ( $S^{\text {rd }}$ regime, $\mathrm{STLR} \approx 1, \mathrm{SSR} \approx 1$ ), the reaction rate may be limited by the availability of $\mathrm{Y}$ at the surface. Assuming that $\mathrm{Y}$ is nonvolatile, a deficit in $\mathrm{Y}$ at the surface is caused by reaction with $\mathrm{X}$ and incomplete mixing with the particle bulk. Thus, we define $\mathrm{SMP}_{\mathrm{Y}}$ as the ratio of the actual surface concentration $[\mathrm{Y}]_{\mathrm{Ss}}$ to the maximum possible surface concentration $[\mathrm{Y}]_{\mathrm{ss}, \max }$ :

$\mathrm{SMP}_{\mathrm{Y}}=\frac{[\mathrm{Y}]_{\mathrm{ss}}}{[\mathrm{Y}]_{\mathrm{ss}, \max }}$

Here we propose $[\mathrm{Y}]_{\mathrm{ss}, \max }=[\mathrm{Y}]_{\mathrm{b} n} \cdot \delta_{\mathrm{Y}}$, namely that the maximum possible surface concentration of $\mathrm{Y}$ should be linked to the bulk concentration at the centre of the particle (layer $n$ ) and a geometric factor $\delta_{\mathrm{Y}}$ to relate the molecular volume concentration $\left(\mathrm{cm}^{-3}\right)$ to a molecular area concentration $\left(\mathrm{cm}^{-2}\right)$. Referencing the surface concentration against the innermost bulk layer gives maximum sensitivity to depthwise gradients in Y. It is important to note that the maximum surface concentration $[\mathrm{Y}]_{\mathrm{ss}, \max }$ may change as the reaction proceeds due to decreased abundance of $\mathrm{Y}$ in layer $n$. The numerical interpretation of $\mathrm{SMP}_{\mathrm{Y}}$ is:

1. As $\mathrm{SMP}_{\mathrm{Y}}$ approaches zero, a strong gradient in $\mathrm{Y}$ exists from the centre of the bulk to the surface of the particle, and the system falls within the bulk diffusion-limited surface reaction case $S_{\mathrm{bd}}$.

2. As $\mathrm{SMP}_{\mathrm{Y}}$ approaches unity, $\mathrm{Y}$ is well-mixed throughout the particle and the system falls within the reactionlimited surface reaction case $\mathrm{S}_{\mathrm{rx}}$.

\section{MP in bulk reaction-diffusion-limited systems}

In bulk reaction-diffusion-limited systems $\left(\mathrm{B}^{\text {rd }}\right.$ regime, $\mathrm{STLR} \approx 0, \mathrm{BSR} \approx 1$ ), a gradient in $\mathrm{X}$ and/or $\mathrm{Y}$ may limit the reaction rate, so that expressions for both the mixing of $\mathrm{X}$ and $\mathrm{Y}$ in the bulk are needed. For both species, the reactodiffusive length will be compared to the particle size to assess the degree of mixing. In general, the reacto-diffusive length is the depth-wise distance over which the concentration of a material decreases to $1 / e$ of its original value. The reactodiffusive length will increase as the diffusivity of the material increases and will decrease as the reaction rate coefficient becomes higher. For compounds $\mathrm{X}$ and $\mathrm{Y}$ which react with one another, the reacto-diffusive length can be expressed as:

$l_{\mathrm{rd}, \mathrm{X}}=\sqrt{\frac{D_{\mathrm{b}, \mathrm{X}}}{k_{\mathrm{BR}} \cdot[\mathrm{Y}]_{\mathrm{eff}}}}$

$l_{\mathrm{rd}, \mathrm{Y}}=\sqrt{\frac{D_{\mathrm{b}, \mathrm{Y}}}{k_{\mathrm{BR}} \cdot[\mathrm{X}]_{\mathrm{eff}}}}$

where $[\mathrm{X}]_{\mathrm{eff}}$ and $[\mathrm{Y}]_{\mathrm{eff}}$ are the effective concentrations of $\mathrm{X}$ and $\mathrm{Y}$ in the region where the reaction occurs and $D_{\mathrm{b}, \mathrm{X}}$ and
$D_{\mathrm{b}, \mathrm{Y}}$ are the diffusion constants of each material in the bulk matrix. This formulation is needed in the case of a strong depth-wise gradient in the reaction partner, in which case the simple average concentration might be misleading. Specifically, we propose that the effective concentration should be calculated as the volume- and loss rate-weighted concentration:

$$
\begin{aligned}
{[\mathrm{X}]_{\mathrm{eff}} } & =\frac{\sum_{k=1}^{n} L_{k} V_{k}[\mathrm{X}]_{\mathrm{b} k}}{\sum_{k=1}^{n} L_{k} V_{k}} \\
{[\mathrm{Y}]_{\mathrm{eff}} } & =\frac{\sum_{k=1}^{n} L_{k} V_{k}[\mathrm{Y}]_{\mathrm{b} k}}{\sum_{k=1}^{n} L_{k} V_{k}}
\end{aligned}
$$

where $V_{k}$ is the volume of the $k$-th layer. This definition of the effective concentration of the reaction partner in the zone where the reaction occurs allows the use of the reactodiffusive length of each species to gauge the degree of mixing of $\mathrm{X}$ and $\mathrm{Y}$ within the particle.

We define the $\mathrm{BMP}_{\mathrm{X}}$ and $\mathrm{BMP}_{\mathrm{Y}}$, the bulk mixing parameters for $\mathrm{X}$ and $\mathrm{Y}$, respectively, to be:

$\begin{aligned} \mathrm{BMP}_{\mathrm{X}} & =\frac{l_{\mathrm{rd}, \mathrm{X}}}{l_{\mathrm{rd}, \mathrm{X}}+\frac{r_{\mathrm{p}}}{e}} \\ \mathrm{BMP}_{\mathrm{Y}} & =\frac{l_{\mathrm{rd}, \mathrm{Y}}}{l_{\mathrm{rd}, \mathrm{Y}}+\frac{r_{\mathrm{p}}}{e}}\end{aligned}$

so that both BMPs approach unity as their reacto-diffusive length becomes much larger than the particle radius $r_{\mathrm{p}}$ and approach zero as their reacto-diffusive length becomes much smaller than the particle radius. In $\mathrm{BMP}_{\mathrm{X}}$ and $\mathrm{BMP}_{Y}$, we have chosen to scale the particle radius by $1 / e$ to be consistent with the e-folding characteristic of the reacto-diffusive length.

Finally, as the presence of a gradient in only one compound is insufficient to drive a system into the $B_{b d}$ limiting case, we define $\mathrm{BMP}_{\mathrm{XY}}$ as the average of $\mathrm{BMP}_{\mathrm{X}}$ and $\mathrm{BMP}_{\mathrm{Y}}$ :

$\mathrm{BMP}_{\mathrm{XY}}=\frac{\mathrm{BMP}_{\mathrm{X}}+\mathrm{BMP}_{\mathrm{Y}}}{2}$

The numerical interpretation of $\mathrm{BMP}_{\mathrm{XY}}$ is:

1. As BMP $\mathrm{XY}$ approaches zero, strong gradients in both $\mathrm{X}$ and $\mathrm{Y}$ limit loss rate and the system falls within the bulk diffusion-limited bulk reaction case $\mathrm{B}_{\mathrm{bd}}$.

2. As $\mathrm{BMP}_{\mathrm{XY}}$ approaches unity, $\mathrm{X}$ and $\mathrm{Y}$ are well-mixed throughout the particle and the system falls within the reaction-limited bulk reaction case $\mathrm{B}_{\mathrm{rx}}$.

A strong gradient solely in bulk $X$ is insufficient to cause bulk diffusion limitation and thus to bring about a $\mathrm{B}_{\mathrm{bd}}$ limiting case classification. For details and justification see Appendix C.

\section{MP in mass transfer-limited systems}

For either bulk or surface reactions (any value of STLR), there are two scenarios which lead to mass transfer limitation 
( $\mathrm{SSR}$ and/or $\mathrm{BSR} \approx 0$ ): either trace gas reactant $\mathrm{X}$ is depleted in the near-surface gas phase (see Fig. 1) or the accommodation process is inefficient. This distinction is important as in the second case a physical or chemical change in the system might result in increased accommodation efficiency, leading to significant changes in reaction system behaviour. A simple and physically meaningful metric to distinguish these two cases is the gas-phase diffusion correction factor for uptake by aerosols (Pöschl et al., 2007), $C_{\mathrm{g}, \mathrm{X}}$, which we take as the gas-phase mixing parameter.

$C_{\mathrm{g}, \mathrm{X}}=\frac{[\mathrm{X}]_{\mathrm{gs}}}{[\mathrm{X}]_{\mathrm{g}}}=\frac{1}{1+\gamma \mathrm{X} \frac{0.75+0.28 K n_{\mathrm{X}}}{K n_{\mathrm{X}}\left(1+K n_{\mathrm{X}}\right)}}$

As can be seen, $C_{\mathrm{g}, \mathrm{X}}$ can be calculated in two ways, either directly via model output of $[X]_{g s}$ and $[X]_{g}$, which are the trace gas concentrations near the surface and far from the particle, respectively; or via model output of $\gamma_{\mathrm{X}}$ and $K n_{\mathrm{X}}$, which are the net uptake coefficient of $\mathrm{X}$ and the Knudsen number of the diffusive system. The Knudsen number (see Pöschl et al., 2007) is the ratio of the mean free path of the trace gas molecule $\lambda_{X}$ to the particle radius, where $\lambda_{X}$ depends on the gas-phase diffusivity $D_{\mathrm{g}, \mathrm{X}}$ and the mean thermal velocity of the gas $\omega_{\mathrm{X}}\left(\lambda_{\mathrm{X}} \approx 70 \mathrm{~nm}\right.$ at atmospheric pressure for ozone $)$ so that

$K n_{\mathrm{X}}=\frac{\lambda_{\mathrm{X}}}{r_{\mathrm{p}}}=\frac{3 D_{\mathrm{g}, \mathrm{X}}}{r_{\mathrm{p}} \omega_{\mathrm{X}}}$.

The numerical interpretation of $C_{\mathrm{g}, \mathrm{X}}$ is:

1. As $C_{\mathrm{g}, \mathrm{X}}$ approaches zero, the system shows a strong spatial gradient in $[\mathrm{X}]_{\mathrm{g}}$ and the system is limited by diffusion of gas phase $\mathrm{X}$ to the particle surface, characteristic for $\mathrm{S}_{\mathrm{gd}}$ or $\mathrm{B}_{\mathrm{gd}}$ limiting cases in the $\mathrm{SB}^{\mathrm{gd}}$ regime.

2. As $C_{\mathrm{g}, \mathrm{X}}$ approaches unity, no spatial concentration gradient exists in $[\mathrm{X}]_{\mathrm{g}}$ and the system is therefore limited by accommodation. It is thus assigned to either a $\mathrm{S}_{\alpha}$ or $\mathrm{B}_{\alpha}$ limiting case (both of which fall within the $\mathrm{SB}^{\alpha}$ regime).

\section{Examples of atmospheric relevance}

The limiting cases described above are meant to provide a conceptual framework for chemical kinetics in atmospheric particles and allow physical and chemical intuition to be applied in a complex system. A few examples of well-known systems which fall into well-defined limiting cases are the following:

\subsection{Well-mixed bulk reaction systems $\left[B_{r x}\right]$}

Many of the slow aqueous phase reactions fall into this limiting case, which arises when both trace gas $\mathrm{X}$ and bulk constituent $\mathrm{Y}$ are plentiful and ubiquitous throughout the particle. This is the case for the reaction of $\mathrm{O}_{3}$ with $\mathrm{SO}_{2}$ under acidic conditions (where formation of $\mathrm{HSO}_{3}^{-}$or $\mathrm{SO}_{3}^{2-}$ is not likely, cf. Seinfeld and Pandis, 2006), the self-reaction of $\mathrm{HO}_{2}$ in absence of transition metal ions (cf. Abbatt et al., 2012, and references therein, especially George et al., 2011), or reactions involving $\mathrm{NO}_{2}$ (Ammann et al., 2005). Such reactions are typically not a major sink of the trace gas involved from the gas phase, but are important in terms of aerosol aging if they are the principle transformation of the condensed phase compound.

\subsection{Well-mixed surface reaction systems $\left[\mathrm{S}_{\mathrm{rx}}\right]$}

Many relevant reactions on solid surfaces, such as ice, mineral dust, or soot fall into this limiting case (e.g. surface oxidation of polycyclic aromatic hydrocarbons by ozone, Shiraiwa et al., 2009). Moreover, gas uptake by liquid aqueous substrates can also be limited by chemical reaction at the surface. For example, the reaction of $\mathrm{Cl}_{2}$ with $\mathrm{Br}^{-}$has a strong surface component, especially at low $\mathrm{Cl}_{2}$ gas-phase concentrations (Hu et al., 1995). Similarly, Knipping et al. (2000) as well as Knipping and Dabdub (2002) suggested a surface reaction between the $\mathrm{OH}$ radical and $\mathrm{Cl}^{-}$under atmospheric conditions via formation of a surface complex (Laskin et al., 2003; Shaka' et al., 2007).

\subsection{Mass transfer-limited systems $\left[\mathbf{S}_{\alpha}, \mathbf{B}_{\alpha} ; \mathbf{S}_{\mathrm{gd}}, \mathbf{B}_{\mathrm{gd}}\right]$}

Surface accommodation limitation necessarily occurs during the equilibration of fresh surface upon exposure to $\mathrm{X}$, e.g. $\mathrm{HCl}$ on $\mathrm{H}_{2} \mathrm{SO}_{4}$ (Morris et al., 2000; Behr et al., 2001, 2009), but also for all other surface precursor mediated processes mentioned above. If transfer into aqueous droplets is fast, bulk accommodation is rate limiting until solubility equilibrium begins to limit uptake. For soluble gases, this may be the dominant case for uptake into the aqueous phase in clouds. Each of the accommodation limited cases mentioned above may become gas-phase diffusion-limited as the particle becomes sufficiently large (and $K n$ becomes small). This may be important in laboratory experiments with supermicron droplets and for cloud droplet or aerosol growth.

\subsection{Bulk diffusion-limited systems $\left[S_{b d}, B_{b d}\right]$}

In the past, reactions in atmospheric aerosols were assumed to occur in well-mixed droplets with no limitation due to diffusion in the condensed phase. However, recent evidence shows that aqueous particles may transition into highly viscous semi-solid or glassy states (Zobrist et al., 2008; Virtanen et al., 2010; Koop et al., 2011), which lead to strong diffusional limitations on reaction rate. Diffusion of one or both reactants in the bulk may become rate limiting. Examples include the nitration of amorphous protein (Shiraiwa et al., 2011a, 2012c), the reaction of $\mathrm{NO}_{3}$ with levoglucosan (Shiraiwa et al., 2012b), and (non-reactive) uptake of water to dissolve a glassy aerosol (Mikhailov et al., 2009; Zobrist et al., 2011; Koop et al., 2011; Tong et al., 2011). 


\subsection{Changes in kinetic behaviour as a function of time and ambient conditions}

Each of the examples given above references a single limiting case, and in many cases the limiting case or regime assignment may remain constant throughout the majority of a reaction. However, the limiting case or kinetic regime will almost certainly change in the first moments of reaction or as reaction products accumulate. For example, in a bulk reaction dominated system, the uptake of soluble trace gases into liquid particles could be initially accommodation-limited $\left(\mathrm{B}_{\alpha}\right)$ and thereafter pass into the bulk diffusion-limited $\mathrm{B}_{\mathrm{bd}}$ case for viscous droplets or into the well-mixed $\mathrm{B}_{\mathrm{rx}}$ case for slow bulk phase reactions. This demonstrates that a system may evolve from one limiting case to another in time. Although time-invariant kinetic parameters are used in the case study of oleic acid-ozone in Sect. 6, the classification system described here is compliant with temporally varying parameters such as changing bulk diffusivities $D_{\mathrm{b}, \mathrm{X}}$ and $D_{\mathrm{b}, \mathrm{Y}}$ as a reaction proceeds (e.g. as in Pfrang et al., 2011). This might occur when reaction products alter the viscosity of the bulk matrix. The classification framework is also independent of model choice; a model that explicitly treats product formation along with evaporation of volatile products could be used with the framework as proposed above.

In addition to noting that the kinetic behaviour will change as the reaction proceeds, we caution against the logical error of assuming that the kinetic regime or limiting case observed in one experiment will be the same under ambient conditions or in another experiment under different conditions. For this reason, we recommend that the limiting case for an aerosol system under ambient conditions should be calculated as part of a standard analysis, especially if experimental conditions are significantly different than ambient. For example, the reaction of ozone with bromide (a potentially important reaction for the liberation of halogens out of aqueous sea-salt) is dominated by a surface reaction $\left(\mathrm{S}_{\mathrm{rx}}\right)$ at atmospherically relevant ozone concentrations, while it is dominated by a bulk reaction $\left(\mathrm{B}_{\mathrm{rx}}\right)$ at very high ozone concentration (Oldridge and Abbatt, 2011).

\section{Numerical modelling of limiting cases}

Up to this point, the limiting cases and regimes have been described in terms of trends in the parameters, but the actual assignment of a reaction system to a limiting case requires a set of numerical criteria and a model to generate the time- and depth-resolved data. In this section we describe our choice of depth-resolved model and propose a set of numerical criteria for differentiation of aerosol behaviour along with a global analysis method to confirm that the numerical criteria result in distinct limiting cases.
Table 2. Kinetic input parameters in the KM-SUB representation of aerosol chemistry.

\begin{tabular}{llc}
\hline Parameter & Description & Units \\
\hline$k_{\mathrm{BR}}$ & $\begin{array}{l}\text { 2nd order bulk reaction rate } \\
\text { coefficient }\end{array}$ & $\mathrm{cm}^{3} \mathrm{~s}^{-1}$ \\
$k_{\mathrm{SLR}}$ & $\begin{array}{l}\text { 2nd order surface reaction } \\
\text { rate coefficient }\end{array}$ & $\mathrm{cm}^{2} \mathrm{~s}^{-1}$ \\
$D_{\mathrm{b}, \mathrm{X}}$ & $\begin{array}{l}\text { Bulk diffusion coefficient of } \\
\text { X in Y }\end{array}$ & $\mathrm{cm}^{2} \mathrm{~s}^{-1}$ \\
$D_{\mathrm{b}, \mathrm{Y}}$ & $\begin{array}{l}\text { Self-diffusion coefficient } \\
\text { of Y }\end{array}$ & $\mathrm{cm}^{2} \mathrm{~s}^{-1}$ \\
$H_{\mathrm{cp}, \mathrm{X}}$ & $\begin{array}{l}\text { Henry's law solubility coefficient } \\
\text { of X in Y }\end{array}$ & $\mathrm{molcm}^{-3} \mathrm{~atm}^{-1}$ \\
$\tau_{\mathrm{d}, \mathrm{X}}$ & $\begin{array}{l}\text { Desorption lifetime of X } \\
\alpha_{\mathrm{s}, 0, \mathrm{X}}\end{array}$ & $\begin{array}{l}\text { Surface accommodation coefficient } \\
\text { of X on bare Y }\end{array}$ \\
$D_{\mathrm{g}, \mathrm{X}}$ & Gas-phase diffusion coefficient of X & $\mathrm{s}^{-}$ \\
\hline
\end{tabular}

\subsection{KM-SUB model description and method}

In the following analyses, we have chosen to employ the KM-SUB model of Shiraiwa et al. (2010), but this set of limiting cases and classification criteria could be used with any model which produces time- and depth-resolved outputs. KM-SUB is a kinetic model that treats mass transport and chemical reaction at the surface and in the bulk of aerosol particles. It follows the nomenclature of the PRA framework and consists of model compartments as outlined in Sect. 2.1 and shown in Fig. 1. KM-SUB solves a set of ordinary differential equations for the flux-based mass balance to and from each layer, resolving the following processes: gas-phase diffusion, adsorption and desorption onto the particle surface, surface-bulk exchange, bulk diffusion of trace gas and bulk material as well as surface and bulk reactions. The original gas-phase diffusion correction term in KM-SUB was replaced by an explicit near-surface gas-phase layer (following the treatment of gas flux through a virtual surface, found in Eq. 12 of Pöschl et al., 2007). Effectively, the kinetic behaviour of a physical system is described in this modified version of KM-SUB by the eight parameters given in Table 2 (not including experimental observables such as particle radius $r_{\mathrm{p}}$, gas phase concentration $[\mathrm{X}]_{\mathrm{g}}$, etc.). The number of layers calculated by the model was adjusted until model results converged to ensure adequate depthwise resolution.

The KM-SUB model was used to calculate idealised limiting case profiles which are not tied to any specific chemical system (see Sect. 5.1) and also to simulate the reaction of oleic acid-ozone for the experimental conditions of Ziemann (2005), Lee and Chan (2007) and Hearn et al. (2005) in Sect. 6. Because the limiting case is likely to change one or more times upon the onset of reaction (see Sect. 3.5), it is necessary to determine the limiting case at a specific point in time or at a specific point in the reaction. Our results show that limiting behaviour tends to be stable over long parts of the simulations after the initial rapid changes. As 
the KM-SUB model does not explicitly treat the products of this reaction, limiting cases were assigned at the point where $50 \%$ of the initial reactant $Y$ was consumed using the numerical criteria of Sect. 4.2. However, in these experiments the limiting case assignments are the same if the assignment is made at either $10 \%$ or $50 \%$ reaction course (see Table 6 below), so comparison with previous studies which used initial rate methods is possible.

\subsection{Numerical criteria and partially defined behaviour}

Even though a system may exhibit steady state reactivity over a long period of time, the situation cannot be necessarily assigned to one of the limiting cases. An ideal system would have binary behaviours (e.g. only surface or bulk reactions, but not both), but in real systems some mixed character is expected. The ability to assign a limiting case (or lack thereof) is thus a consequence of the physical system under study and the conditions of each experiment. The exact positions of such boundaries for limiting cases and regimes are rather subjective and may change depending on the application. Here, we employ a 9:1 criterion for limiting cases, such that at least $90 \%$ of the behaviour is represented by the kinetic regime definition at each classification step. The boundaries for regimes are more relaxed at $3: 1$ criteria, so that more space can be classified. Although knowledge of the system's kinetic regime is less valuable than the confirmation of (single-process) limiting behaviour, such a classification might still be useful. Prominent examples of systems which could be classified by a regime, but not a limiting case are heterogeneous kinetics in the bulk reactiondiffusion kinetic regime $\left(\mathrm{B}^{\text {rd }}\right)$, such as the reaction of $\mathrm{HCl}$ with $\mathrm{HOCl}$ in sulfuric acid solutions (Hanson and Lovejoy, 1996; Donaldson et al., 1997, and references therein), the hydrolysis of $\mathrm{ClONO}_{2}$ (Deiber et al., 2004), or the reaction of $\mathrm{O}_{3}$ with iodide (Rouvière et al., 2010). In these examples, kinetic regimes can help by providing a less stringent classification than a limiting case. However, unless the numerical criteria are set at $1: 1$ with no unspecified region, there will be some combinations of classification parameters for which no assignment is possible.

\subsection{Global sensitivity analysis}

The best indication that an assignment to a limiting case is justified and that the choice of numerical criteria is sufficiently strict is given by a sensitivity analysis which confirms that the system is controlled by a single process and responds appropriately to changes in the associated input parameters (e.g. $\mathrm{S}_{\alpha}$ cases should depend only on the surface accommodation coefficient $\alpha_{\mathrm{s}, 0}$ and not on the surface reaction rate coefficient $k_{\mathrm{SLR}}$ etc.). In general, sensitivity towards an input parameter $\lambda_{i}$ can be expressed through its sensitivity coeffi- cient $S\left(\lambda_{i}\right)$, which may be defined as

$S\left(\lambda_{i}\right)=\left(\frac{\Delta Y_{\text {model }}}{\Delta \lambda_{i}}\right)$.

However, the values of $S_{i}$ cannot be compared directly because they depend on the magnitudes of the input parameters $\left(\lambda_{i}\right)$ which are being varied and the observed model output $Y_{\text {model }}$. Thus we employ a normalised sensitivity coefficient (following Saltelli et al., 2008) which allows the influence of input parameters to be directly compared:

$S^{n}\left(\lambda_{i}\right)=\frac{\frac{1}{Y_{\text {model }}} \partial Y_{\text {model }}}{\frac{1}{\lambda_{i}} \partial \lambda_{i}}=\frac{\partial \ln \left(Y_{\text {model }}\right)}{\partial \ln \left(\lambda_{i}\right)}$

For the computation of sensitivity coefficients we employ a variation on the Elementary Effects (EE) Method as proposed by Morris (1991). The EE method is a simple global screening method that uses a one-at-a-time sampling approach (other approaches are also possible, for a summary see e.g. Saltelli et al., 2008). The method follows a randomly generated trajectory through input parameter space, and records the changes in model output $Y_{\text {model }}$ due to changes in each input parameter $\lambda_{i}$. Only one parameter is varied at each step, and all previous changes are kept, which leads to generation of a full set of local sensitivity coefficients. To account for biases due to the random trajectory generation, a large number of trajectories are generated and a representative sample is chosen so that the entire input parameter space is adequately represented. The global sensitivity coefficient is thus finally obtained by taking the arithmetic mean $\mu_{i}$ of all computed local values. The associated standard deviation $\sigma_{i}$ is a measure for interactions between and nonlinearity of the input parameters $\lambda_{i}$.

In this study, we use the total loss rate, $L_{\text {tot }}=L_{\mathrm{s}}+\sum_{k} L_{k}$, as model output characteristic for the reaction system. The result of this analysis is a set of normalised sensitivity coefficients, which indicate the strength of the model response to changes in each input parameter. Crucially, this sensitivity analysis is only possible in the context of a specific chemical system, physical size (distribution) of aerosol particles, and for a given set of kinetic constants. For this study we perform sensitivity analyses in the context of the oleic acid-ozone system (see Sect. 6.5 below), but recommend the analysis to be performed for each new system to ensure that appropriate numerical limits are chosen. Even within the same chemical system with the same kinetic constants, the calculated sensitivities will change in response to differing experimental conditions such as gas-phase oxidant concentration or particle size.

The interpretation of the normalised sensitivity coefficients can be achieved by connecting the input parameter $\lambda_{i}$ to the original model output $Y_{\text {model }}$ by the power law relationship:

$Y_{\text {model }} \propto \lambda_{i}^{S^{n}\left(\lambda_{i}\right)}$. 
In words, this indicates that the model output responds to changes in input parameter $\lambda_{i}$ in proportion to the $S^{n}\left(\lambda_{i}\right)$ th power of the change. For example, a $S^{n}\left(\lambda_{i}\right)$ of -1 would indicate inverse dependence on input parameter $\lambda_{i}$ etc.

\section{Identification of limiting cases and scaling from laboratory to ambient conditions}

The limiting cases and regimes described above are essentially statements of which underlying processes are most influential to a reaction for a given set of conditions. As such, they have the potential to aid experimental planning by suggesting which parameters should be adjusted to maximise experimental effectiveness. If the underlying kinetic parameters such as reaction rate coefficients and diffusivities are extracted from experimental data, these parameters would provide direct insight into the physicochemical processes at work in the system and are portable to different conditions.

However, the kinetic parameters of a system can be obtained only from comprehensive studies, often requiring fits to data from multiple experiments. Without these parameters it is not possible to perform calculations with a depthresolved model to make an immediate assignment of limiting case or regime behaviour. Fortunately, the limiting cases display some characteristic behaviours which can provide insight into the reaction system from experimental observables (e.g. reactive uptake coefficient as a function of time) and from responses to controlled variables (e.g. change in reactive uptake coefficient $\gamma_{\mathrm{X}}$ as a function of particle radius $r_{\mathrm{p}}$ or gas-phase oxidant concentration $[\mathrm{X}]_{\mathrm{g}}$ ). In this section we will present the characteristic behaviours of the limiting cases and summarise how each limiting case behaves with respect to time, $r_{\mathrm{p}}$, and $[\mathrm{X}]_{\mathrm{g}}$, which will allow an experimentalist to narrow the list of possible limiting cases by visual inspection of experimental data and possibly plan future experiments based on those conclusions.

In particular, the sensitivity coefficients given in Sect. 5.2 provide an indication of how experimental results will change as a function of time or other experimentally controllable factors like $r_{\mathrm{p}}$ or oxidant concentration. In the discussion that follows we will give special attention to the interchangeability of time and oxidant concentration, which is a necessary condition for usage of the net exposure metric (concentration of oxidant $\times$ time) for application to atmospheric concentrations and time scales. Renbaum and Smith (2011) recently showed that under constant precursor concentrations, the exposure metric was valid for the reaction of $\mathrm{OH}$ and $\mathrm{Cl}$ radicals with squalane, brassidic acid, and 2octyldodecanoic acid. However, other studies have found that the exposure metric breaks down when scaling from laboratory to ambient conditions, as summarised by Renbaum and Smith (2011).

\subsection{Characteristic decay shapes}

An overview of the eight distinct limiting cases and several regimes is given in Table 3 along with their characteristic limiting process(es). Each limiting case has a single ratelimiting process by definition and exhibits a characteristic behaviour as a function of time. A set of idealised KM-SUB parameter sets has been obtained by modifying the typical base case for the reaction oleic acid and ozone, see Appendix D for details.

The computed behaviours for these archetypal limiting cases are shown in Fig. 5 as a function of time for the total number of molecule $\mathrm{Y}$ remaining $\left(N_{\mathrm{Y}}\right)$ and for the effective uptake coefficient $\left(\gamma_{\mathrm{eff}, \mathrm{X}}=\gamma_{\mathrm{X}} \cdot C_{\mathrm{g}, \mathrm{X}}\right)$. These two quantities are the observables in experimental studies which in general either measure bulk $\mathrm{Y}\left(N_{\mathrm{Y}}\right)$ or gas-phase $\mathrm{X}\left(\gamma_{\mathrm{eff}, \mathrm{X}}\right)$. Typical data for $N_{Y}$ are shown on a linear time axis with linear (Fig. 5a) and logarithmic (Fig. 5b) y-axes. Data for $\gamma_{\text {eff,X }}$ are shown on a logarithmic y-axis with a linear (Fig. 5c.) and logarithmic (Fig. 5d) time axis. All $N_{\mathrm{Y}}$ data are normalised against the initial value $N_{Y, 0}$ and all time data are scaled to $t_{99}$ (the time at which $99 \%$ of the bulk material has reacted).

A set of limiting cases showing linear decay behaviour of $N_{\mathrm{Y}}$ in time $\left(\mathrm{S}_{\alpha}, \mathrm{B}_{\alpha}, \mathrm{S}_{\mathrm{gd}}, \mathrm{B}_{\mathrm{gd}}\right.$; see panel a) arises when transport over a certain interface creates a bottle-neck that limits the reaction (effectively, a 0-th order-type reaction). In panels $\mathrm{c}$ and $\mathrm{d}$, these behaviours are characterised by timeinvariant values of $\gamma_{\text {eff,X. }}$. As opposed to panels a and $b$, not all lines with similar shape are overlapping since reaction speeds slightly differ between the chosen input parameter sets and no normalisation for $\gamma_{\mathrm{eff}, \mathrm{X}}$ has been carried out. However, the qualitative lineshape is consistent, independent of the actual reaction speed.

In panel $b$, the $B_{\mathrm{rx}}$ and $\mathrm{S}_{\mathrm{rx}}$ cases appear linear and can therefore be classified as mono-exponential decays, pointing towards a first-order type process. A similar shape is found for the $S_{b d}$ case after an initial fast decay that might be due to quick depletion of near-surface bulk layers. Hence, the system is not a true $S_{b d}$ limiting case in the first moments of the reaction as the gradient in Y has yet to develop. The initial decay of $\gamma_{\text {eff, } \mathrm{X}}$ for the $\mathrm{S}_{\mathrm{bd}}$ case is well-resolved in panel $\mathrm{d}$, showing a linear decrease in log-log space with slope $\frac{1}{2}$. This is characteristic for cases that are not in reacto-diffusive steady state, an inherent property of bulk diffusion-limited cases.

The same initial decay of $\gamma_{\text {eff, } X}$ can thus be found for the $\mathrm{B}_{\mathrm{bd}}$ limiting case (bulk reaction limited by bulk diffusion). This case furthermore shows a nonlinear, higher-order exponential decay in $N_{\mathrm{Y}}$ as characteristic feature (panels a and b). The reaction slows down significantly once the diffusional gradients in $\mathrm{X}$ and $\mathrm{Y}$ are developed. As the rate of formation of the gradients and the location where the gradients form is not prescribed, this limiting case is expected to encompass a range of behaviours and will not have a single defining characteristic. 
Table 3. List of kinetic regimes and limiting cases and their respective controlling processes. Limiting cases are characterised by being controlled by one process, while systems in the regimes shown here are controlled by at most two processes. The parameters which influence the processes are given in a separate column and are defined in Table 2.

\begin{tabular}{|c|c|c|c|c|c|}
\hline Limiting Processes & Parameters & \multicolumn{2}{|c|}{ Regime/Limiting Case } & Limiting Process & Parameter(s) \\
\hline Reaction and diffusion (surface) & $k_{\mathrm{SLR}}, D_{\mathrm{b}, \mathrm{Y}}, K_{\mathrm{ads}}$ & $S^{\text {rd }}$ & $\begin{array}{l}S_{\mathrm{rx}} \\
\mathrm{S}_{\mathrm{bd}}\end{array}$ & $\begin{array}{l}\text { Chemical reaction at surface } \\
\text { Bulk diffusion of } Y\end{array}$ & $\begin{array}{l}k_{\mathrm{SLR}}, K_{\mathrm{ads}}^{\mathrm{a}} \\
D_{\mathrm{b}, \mathrm{Y}}\end{array}$ \\
\hline Mass transfer of $X$ to surface & $\alpha_{\mathrm{s}, 0, \mathrm{X}}, D_{\mathrm{g}, \mathrm{X}}$ & $\mathrm{S}^{\mathrm{mt}}$ & $\begin{array}{l}\mathrm{S}_{\alpha} \\
\mathrm{S}_{\mathrm{gd}}\end{array}$ & $\begin{array}{l}\text { Surface accommodation of } X \\
\text { Gas-phase diffusion of } X\end{array}$ & $\begin{array}{c}\alpha_{\mathrm{s}, 0, \mathrm{X}} \\
D_{\mathrm{g}, \mathrm{X}}\end{array}$ \\
\hline Reaction and diffusion (bulk) & $k_{\mathrm{BR}}, D_{\mathrm{b}, \mathrm{X}}, D_{\mathrm{b}, \mathrm{Y}}, H_{\mathrm{X}}$ & $\mathrm{B}^{\mathrm{rd}}$ & $\begin{array}{l}\mathrm{B}_{\mathrm{rx}} \\
\mathrm{B}_{\text {trad }}^{\mathrm{rd}} \\
\mathrm{B}_{\mathrm{bd}}\end{array}$ & $\begin{array}{l}\text { Chemical reaction in bulk } \\
\text { Equal parts reaction and diffusion } \\
\text { Bulk diffusion of } \mathrm{X} \text { and } \mathrm{Y}\end{array}$ & $\begin{array}{l}k_{\mathrm{BR}}, H_{\mathrm{X}} \\
k_{\mathrm{BR}}, D_{\mathrm{b}, \mathrm{X}}, H_{\mathrm{X}} \\
D_{\mathrm{b}, \mathrm{X}}, H_{\mathrm{X}}, D_{\mathrm{b}, \mathrm{Y}}\end{array}$ \\
\hline Mass transfer of $\mathrm{X}$ to bulk & $\alpha_{\mathrm{s}, 0, \mathrm{X}}, D_{\mathrm{g}, \mathrm{X}}, D_{\mathrm{b}, \mathrm{X}}, H_{\mathrm{X}}$ & $\mathrm{B}^{\mathrm{mt}}$ & $\left\{\begin{array}{l}\mathrm{B}_{\alpha} \\
\mathrm{B}_{\mathrm{gd}}\end{array}\right.$ & $\begin{array}{l}\text { Bulk accommodation of } \mathrm{X} \\
\text { Gas-phase diffusion of } \mathrm{X}\end{array}$ & $\begin{array}{l}\alpha_{\mathrm{s}, 0, \mathrm{X}}, D_{\mathrm{b}, \mathrm{X}}, H_{\mathrm{X}}^{\mathrm{b}} \\
D_{\mathrm{g}, \mathrm{X}}\end{array}$ \\
\hline
\end{tabular}

${ }^{\mathrm{a}} K_{\mathrm{ads}}$ is not a direct input parameter of the model, but inherently depends on $\tau_{\mathrm{d}, \mathrm{X}}$ and $\alpha_{\mathrm{S}, 0, \mathrm{X}}$ as shown in Eq. (4).

$\mathrm{b}$ These parameters altogether determine the bulk accommodation coefficient $\alpha_{\mathrm{b}, \mathrm{X}}$.

(a) charact. shapes of $N_{Y}$ vs. $t$

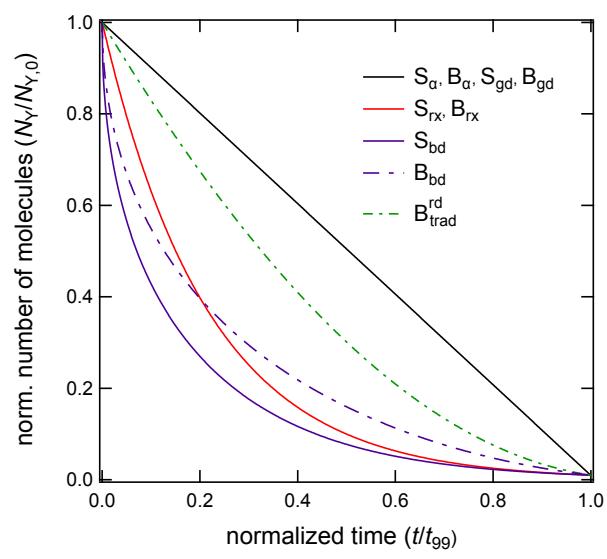

(c) charact. shapes of $\log _{10}(\mathrm{Y})$ vs. $t$

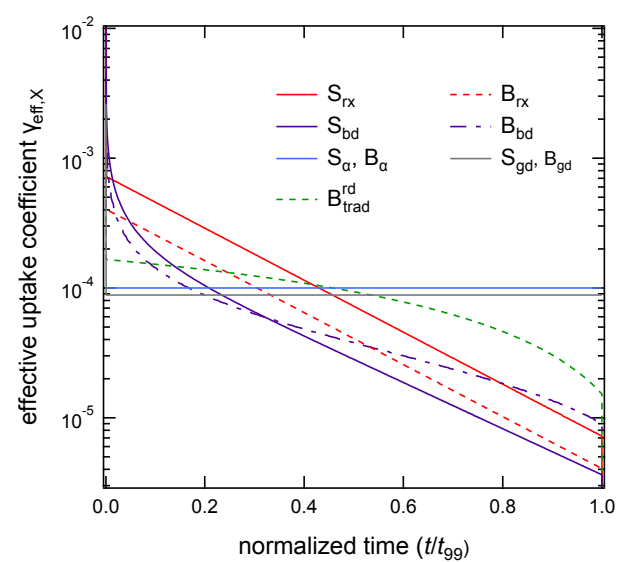

(b) charact. shapes of $\log _{10}\left(N_{Y}\right)$ vs. $t$

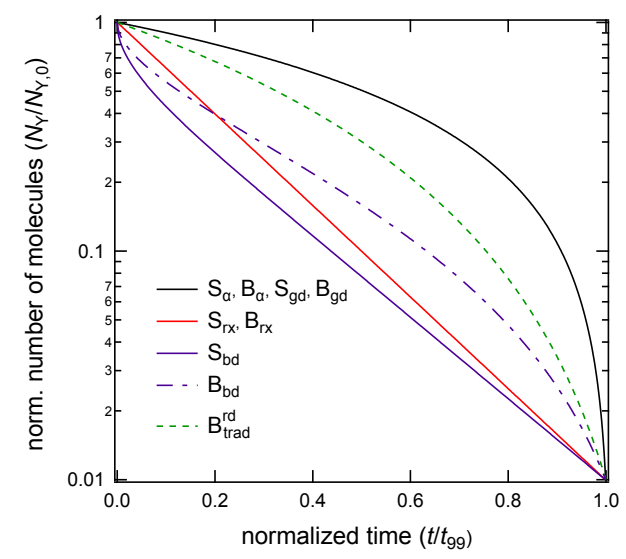

(d) charact. shapes of $\log _{10}(\mathrm{Y})$ vs. $\log _{10}(t)$

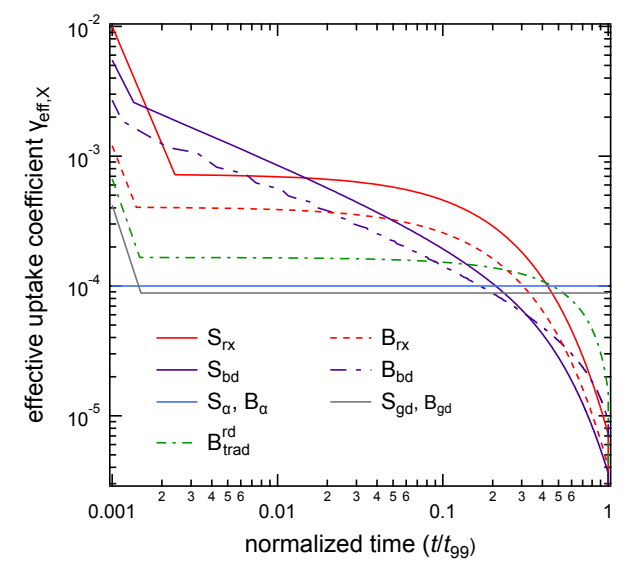

Fig. 5. Normalised representation of the decay shapes of the total amount of $Y\left(N_{Y}\right.$, panels a and b) and the effective reactive uptake

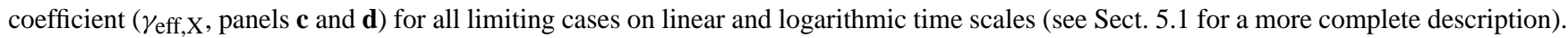
In addition to the eight regular limiting cases, we also display the traditional reacto-diffusive case, $\mathrm{B}_{\text {trad }}^{\text {rd }}$. Note that $\mathrm{B}_{\text {trad }}^{\text {rd }}$ is not a limiting case, but a distinct scenario in the reaction-diffusion regime. 
Table 4. Scalability of limiting cases with respect to $r_{\mathrm{p}}$ and $[\mathrm{X}]_{\mathrm{g}}$ expressed by the normalised sensitivity coefficient of each archetypal case (see Eq. 19). Square brackets indicate the range of possible values.

\begin{tabular}{lcc}
\hline Limiting Case & $S^{n}(\mathrm{rp})$ & $S^{n}([\mathrm{X}] \mathrm{g})$ \\
\hline $\mathrm{S}_{\mathrm{rx}}$ & -1 & {$[0,1]$} \\
$\mathrm{S}_{\mathrm{bd}}$ & -2 & 0 \\
$\mathrm{~S}_{\alpha}$ & -1 & 1 \\
$\mathrm{~S}_{\mathrm{gd}}$ & -2 & 1 \\
$\mathrm{~B}_{\mathrm{rx}}$ & 0 & 1 \\
$\mathrm{~B}_{\mathrm{bd}}$ & -2 & {$[\sim 0,1]$} \\
$\mathrm{B}_{\alpha}$ & {$[-2,-1]$} & 1 \\
$\mathrm{~B}_{\mathrm{gd}}^{\mathrm{rd}} *$ & -2 & 1 \\
$\mathrm{~B}_{\text {trad }}^{\mathrm{rd}}$ & -1 & 1 \\
\hline
\end{tabular}

* Note that $\mathrm{B}_{\text {trad }}^{\text {rd }}$ is not a limiting case, but a distinct scenario in the reaction-diffusion regime.

In addition to the eight limiting cases, the traditional reacto-diffusive bulk reaction case $\mathrm{B}_{\text {trad }}^{\text {rd }}$ can be recognised by showing a quadratic decay of $N_{\mathrm{Y}}$ as a function of time in linear space. In panel d, it resembles the $\mathrm{S}_{\mathrm{rx}}$ and $\mathrm{B}_{\mathrm{rx}}$ cases, but can be distinguished from those two in the linear representation, panel c.

\subsection{Scalability of each limiting case}

The typical response of each limiting case to changes in oxidant concentration $[\mathrm{X}]_{\mathrm{g}}$ and particle radius $r_{\mathrm{p}}$ was investigated using the global sensitivity method described in Sect. 4.3 and the results are given in Table 4. The standard kinetic method of performing "experiments" (here, simulations) at differing $[\mathrm{X}]_{\mathrm{g}}$ and $r_{\mathrm{p}}$ to determine the response (linear, inverse, etc.) yielded identical results. The results of the sensitivity analysis performed on the limiting cases displayed above indicate that the exposure metric is acceptable to use (i.e. linear response to $[\mathrm{X}]_{\mathrm{g}}, S^{n}\left([\mathrm{X}]_{\mathrm{g}}\right)=1$ ) as long as a transport process is not saturated.

In the example of $S_{\mathrm{rx}}$ behaviour above, all surface sites were occupied (surface coverages $\theta_{\mathrm{s}, \mathrm{sat}}=\theta_{\mathrm{s}, \max }=1$ and $\theta_{\mathrm{s}} \approx$ $\left.\theta_{\mathrm{s}, \mathrm{sat}}\right)$ and thus changes in $[\mathrm{X}]_{\mathrm{g}}$ had no effect on the reaction rate. In this situation, it is typical that the measured uptake coefficient $\gamma_{\mathrm{X}}$ is inversely proportional to $[\mathrm{X}]_{\mathrm{g}}$. However, $\mathrm{S}_{\mathrm{rX}}$ behaviour can also be observed when $\theta_{\mathrm{s} \text {,sat }}<\theta_{\mathrm{s} \text {, max }}$ if the adsorption equilibrium constant $K_{\text {ads }}$ dictates that only partial surface coverage can be achieved at equilibrium with gasphase $\mathrm{X}$ (here $\theta_{\mathrm{s}} \approx \theta_{\mathrm{s} \text {,sat }}$, but $\theta_{\mathrm{s} \text {,sat }}<\theta_{\mathrm{s} \text {,max }}$ ). Here, increasing $[\mathrm{X}]_{\mathrm{g}}$ will increase the surface coverage, leading to a faster overall rate of reaction. In this non-saturated $S_{\mathrm{rx}}$ case, the gas uptake is thus also sensitive to $K_{\text {ads }}$, which in turn depends on both accommodation coefficient $\alpha_{\mathrm{s}, 0}$ and desorption lifetime $\tau_{\mathrm{d}}$.

The lack of sensitivity to $[\mathrm{X}]_{\mathrm{g}}$ in the bulk diffusion-limited cases $\left(S_{b d}\right.$ and $B_{b d}$, see Table 4$)$ arises due to the rate- limitation that the diffusion of $\mathrm{Y}$ poses. This process is obviously not accelerated by an increase in trace gas concentration. Thus, $\mathrm{S}_{\mathrm{bd}}$ behaviour, which is entirely limited by diffusion of $\mathrm{Y}$, shows no dependence on $[\mathrm{X}]_{\mathrm{g}}$. $\mathrm{B}_{\mathrm{bd}}$ cases still respond to an increase in $[\mathrm{X}]_{\mathrm{g}}$ since the combined diffusion of $\mathrm{X}$ and $\mathrm{Y}$ is rate-limiting here. Thus, the sensitivity to $[\mathrm{X}]_{\mathrm{g}}$ will always be smaller than unity but higher than zero in a $\mathrm{B}_{\mathrm{bd}}$ case.

Thus, in addition to the explanations already offered for failures of scalability (e.g. secondary chemistry, absorption of other gases etc., see Renbaum and Smith, 2011), we found that systems in which the transport from bulk material to the reaction site is rate limiting (i.e. $S_{b d}$ and $B_{b d}$ behaviour) or surface saturation effects play a role (certain $S_{\mathrm{rx}}$ cases with $\left.\theta_{\mathrm{s}}=\theta_{\mathrm{s}, \mathrm{sat}} \approx \theta_{\mathrm{s}, \max }\right)$ will not act in accordance with the exposure metric.

The sensitivity analysis also provided information on the expected response of each limiting case to changes in particle size. The data displayed in Table 4 for $S^{n}\left(r_{\mathrm{p}}\right)$ show the influence of particle size on reactive half-life. Using Eq. 19 to interpret the sensitivity coefficients, these results show that the reactive half-life of systems which are limited by surfacerelated processes have an inverse dependence on particle size $\left(S^{n}\left(r_{\mathrm{p}}\right)=-1\right)$, systems which are limited by diffusion have an inverse-square dependence on particle size $\left(S^{n}\left(r_{\mathrm{p}}\right)=-2\right)$, and that the $\mathrm{B}_{\mathrm{rx}}$ limiting case does not depend on particle size at all $\left(S^{n}\left(r_{\mathrm{p}}\right)=0\right)$. We note that in bulk accommodationlimited bulk reaction cases, $\mathrm{B}_{\alpha}$, the value of $S^{n}\left(r_{\mathrm{p}}\right)$ is typically -1 if limitation arises due to inefficient accommodation of $\mathrm{X}$ on the surface, but may decrease to -2 when transport across the surface-bulk interface is the rate-limiting step. For a more detailed description of these two different $\mathrm{B}_{\alpha}$ scenarios, see Appendix C.

Taken together, these characteristic behaviours and sensitivities can provide some insight into an experiment based only on the raw data. After making a preliminary assignment based on the decay shape of one dataset, the sensitivities in Sect. 5.2 can be used together with additional experiments to confirm this assignment.

\section{Case study: the oleic acid-ozone reaction system}

The oleic acid-ozone reaction system is an extremely well studied system which has often been used as a benchmark for heterogeneous chemistry systems (see, e.g. the review of Zahardis and Petrucci, 2007), so it is reasonable that we apply the proposed classification scheme to this reaction system. We emphasise that this case study is meant to demonstrate the applicability of the classification system and is not intended to infer new mechanistic information on the oleic acid system.

We will begin with a brief overview of the current state of the art in modelling this system and then apply the classification scheme described above to previously published 
datasets. A comparison of these results with one another and with current work is difficult as each study uses a different nomenclature for the limiting cases which they consider. In the following discussion, the common symbol set proposed above will be used to facilitate comparisons between previous studies and this work. We stress that our fits to the experimental data are not equally likely to represent reality and we do not attempt to judge between them.

\subsection{Background}

In the past, limiting cases similar to those discussed here have been derived by both Smith et al. (2002) and Worsnop et al. (2002) for this reaction system, including resistor modelbased analytical expressions for comparison to experimental results. In the era before depth-resolved computation of aerosol reaction was common, Smith et al. (2003) solved the partial differential equations of diffusion and reaction for this system to provide results resolved in time and depth, but assumed the surface was saturated with respect to trace gas, a crucial assumption which disallows mass transfer-limited behaviour and constrains all results to the reaction-diffusion regime.

The relationships between the limiting cases proposed here and those already published by Smith et al. (2002) (including revisions made in Hearn et al., 2005) as well as in Worsnop et al. (2002) are depicted in Table 5. The most striking differences between these cases and previous schemes is the under-representation of the mass transfer regime: although Worsnop et al. offer a mass transfer-limited case, this only applies to a bulk reaction and is not necessarily a case limited by a single process. It thus represents a range of cases, all of which fall within our definition of the $\mathrm{B}^{\mathrm{mt}}$ regime (bulk reactions limited by mass transfer). Furthermore, we consider Case 2 of Worsnop et al. (2002), Case 1b of Smith et al. (2002) and Case 2 of Hearn et al. (2005) to be representations of the traditional reacto-diffusive case $\mathrm{B}_{\text {trad }}^{\text {rd }}$ within the reaction-diffusion regime, as all have a formulation which shows dependence on both the diffusion of $\mathrm{X}$ and the reaction rate coefficient and thus depend on more than one process to determine reactive uptake. To achieve true bulk diffusionlimited behaviour for such a system ( $\mathrm{B}_{\mathrm{bd}}$ limiting case), the reacto-diffusive length of both $\mathrm{X}$ and $\mathrm{Y}$ must be exceedingly short.

\subsection{Ziemann (2005) dataset}

A well-supported kinetic parameter set for the oleic acidozone reaction system is provided by Pfrang et al. (2010), which used the accommodation coefficient $\alpha_{\mathrm{s}, 0, \mathrm{X}}$ as a fitting parameter to match model output to the experimental results of Ziemann (2005). In that study, the decreasing oleic acid content of $200 \mathrm{~nm}$ radius particles reacting with ozone at a molecular number density of $\sim 6.95 \times 10^{13} \mathrm{~cm}^{-3}$ in an environmental chamber was measured via Thermal Desorp-
Table 5. Comparison of limiting cases proposed in this study to cases of the oleic acid-ozone system in previous studies. A “-” symbol indicates no relationship. The numberings refer to the nomenclature in the original publications.

\begin{tabular}{|c|c|c|c|}
\hline This study & $\begin{array}{l}\text { Worsnop et al. } \\
\quad(2002)\end{array}$ & $\begin{array}{l}\text { Smith et al. } \\
\quad(2002)\end{array}$ & $\begin{array}{l}\text { Hearn et al. } \\
\text { (2005) }\end{array}$ \\
\hline$S_{r x}$ & Case 4 & Case 2 & Case 3 \\
\hline$S_{b d}$ & Case 5 & - & Case 4 \\
\hline $\mathrm{S}_{\alpha}$ & - & - & - \\
\hline$S_{g_{d}}$ & - & - & - \\
\hline $\mathrm{B}_{\mathrm{rx}}$ & Case 3 & Case 1a & Case 1 \\
\hline $\mathrm{B}_{\text {trad }}^{\mathrm{rd}}$ a & Case 2 & Case $1 \mathrm{~b}$ & Case 2 \\
\hline $\mathrm{B}_{\mathrm{bd}}$ & - & - & - \\
\hline $\mathrm{B}_{\alpha}$ & Case $1^{b}$ & - & - \\
\hline $\left.\mathrm{B}_{\mathrm{gd}}\right\}$ & Case $1^{0}$ & - & - \\
\hline
\end{tabular}

a Note that $\mathrm{B}_{\text {trad }}^{\mathrm{rd}}$ is not a limiting case, but a distinct scenario in the
reaction-diffusion regime.
b Case 1 of Worsnop et al. (2002) includes a range of cases inside the $\mathrm{B}^{\mathrm{mt}}$
regime.

tion Particle Beam Mass Spectrometry. The parameter set of Pfrang et al. is displayed in column 2 of Table 6 and will be referred to as base case 1 (bc1). The bc1 parameter set does not include a gas-phase diffusivity of ozone in air. Unless otherwise noted, we used $D_{\mathrm{g}, \mathrm{X}}=0.14 \mathrm{~cm}^{2} \mathrm{~s}^{-1}$ (Massman, 1998). We begin our analysis by replicating the bc1 fit from Pfrang et al. (2010), resulting in very good agreement with the experimental data as shown in Fig. 6a. While this fit does not fall into a limiting case (see Sect. 4.2), it shows low values for both saturation ratios SSR and BSR as well as a gas phase mixing parameter $C_{\mathrm{g}, \mathrm{X}} \sim 1$, altogether indicative of the $\mathrm{SB}^{\alpha}$ regime (see Fig. 3b). The classification parameters are given along with the input parameter values in Table 6 for two different points in reaction course.

Although the bc1 parameter set provides an excellent fit to the experimental results of Ziemann (2005), other studies have provided additional information which suggest that the oleic acid diffusion coefficient $D_{\mathrm{b}, \mathrm{Y}}$ is significantly higher than the original value of $1 \times 10^{-10} \mathrm{~cm}^{2} \mathrm{~s}^{-1}$ (Shiraiwa et al., 2012a; Hearn et al., 2005) and that the desorption lifetime of ozone $\left(\tau_{\mathrm{d}, \mathrm{X}}\right)$ is in the order of nanoseconds for polycyclic aromatic hydrocarbons (PAH, cf. Maranzana et al., 2005; Shiraiwa et al., 2011b) as well as for graphene (Lee et al., 2009). In a modified fit, bc $1^{*}$ (Table 6, column 3), we adopt the value proposed by Shiraiwa et al. (2012a), $1.9 \times 10^{-7} \mathrm{~cm}^{2} \mathrm{~s}^{-1}$ and set $\tau_{\mathrm{d}, \mathrm{X}}=1 \times 10^{-8} \mathrm{~s}$. The change in $D_{\mathrm{b}, \mathrm{Y}}$ has only a small impact on the overall reaction speed, as diffusion of oleic acid is not involved in the limiting process (accommodation of ozone to the surface). The reduced surface desorption lifetime decreases the role of surface reactions so that the modified bc $1^{*}$ can be assigned $\mathrm{B}_{\alpha}$ behaviour. The fit is also displayed in Fig. $6 \mathrm{a}$. 
(a) fits to data in Ziemann (2005)

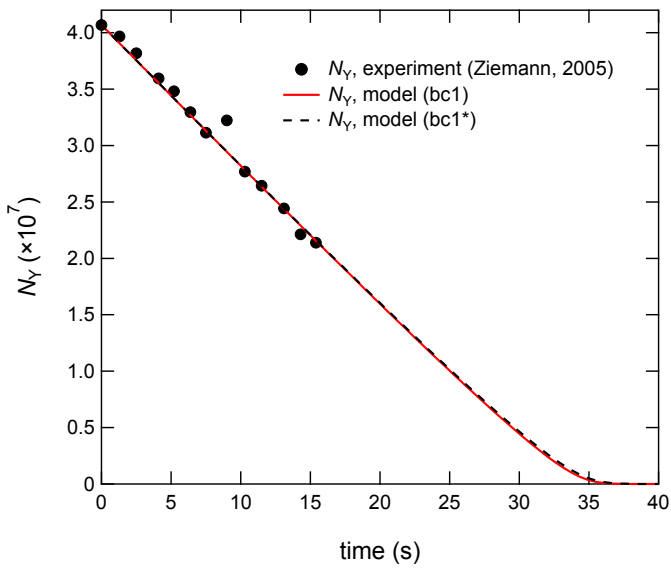

(c) fits to data in Hearn et al. (2005) (linear plot)

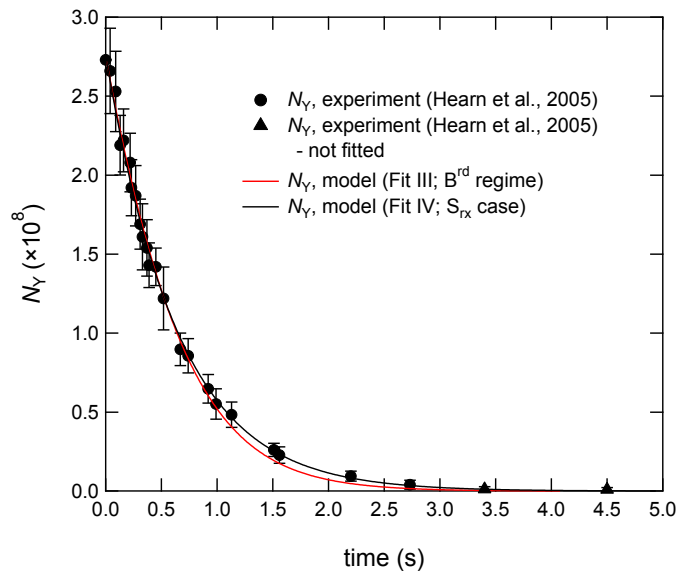

(b) fits to data in Lee and Chan (2007)

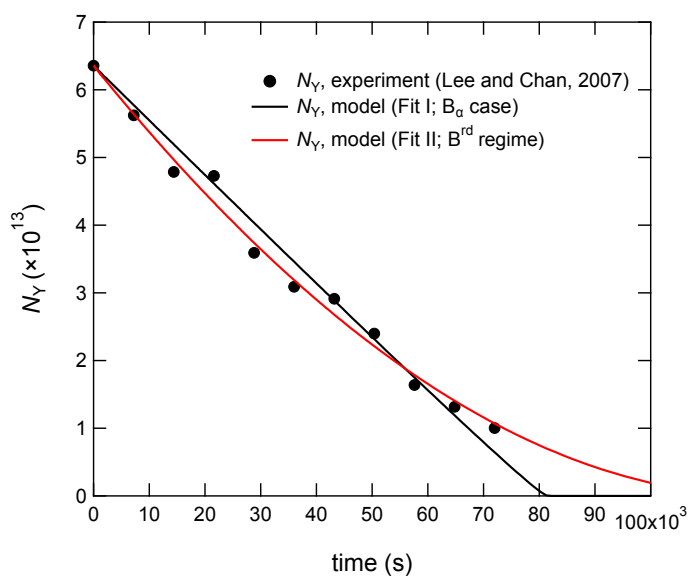

(d) fits to data in Hearn et al. (2005) (logarithmic plot)

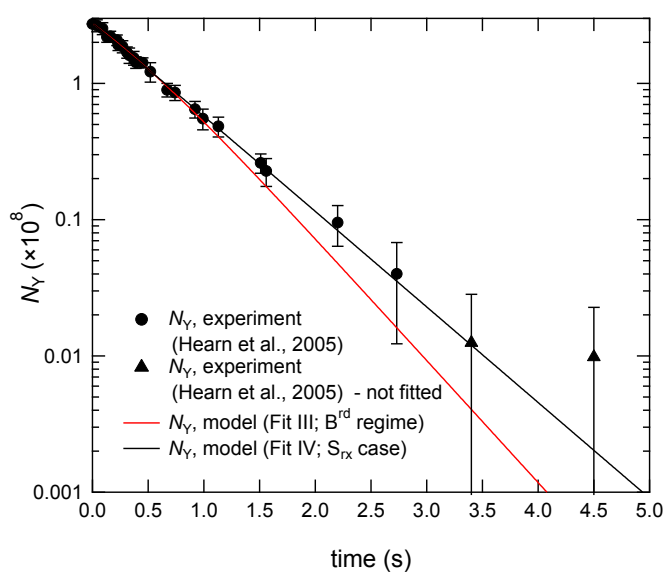

Fig. 6. Comparison of experimental and modelled data of various limiting cases, using time invariant kinetic parameters. In (a) the two parameter sets bc1 and bc $1^{*}$ lead to the same correlation with the experimental data and show the appropriate linear decay. In (b), data from Lee and Chan (2007) show another mostly linear decay of bulk material. This can be realised with two KM-SUB parameter sets similar to bc1* showing $\mathrm{B}_{\alpha}$ and $\mathrm{B}^{\text {rd }}$ behaviour, respectively. In (c), data from Hearn et al. (2005) show a nonlinear decay that thus can not be described by accommodation-limited cases. The $\mathrm{B}^{\text {rd }}$ and $\mathrm{S}_{\mathrm{rx}}$ fits shown are in excellent agreement with the experimental data. (d) reveals in a logarithmic representation that the quality of Fit III is lower after $\sim 2 \mathrm{~s}$ and $85 \%$ of the reaction. The last two points of this dataset (black triangles) were excluded from the fit as their value is not significantly different from zero.

\subsection{Lee and Chan (2007) dataset}

Lee and Chan (2007) used raman spectroscopy to measure the decay of oleic acid in particles exposed to $\sim 6.36 \times$ $10^{12} \mathrm{~cm}^{-3}$ ozone in an electrodynamic balance. We apply a multi-parameter fit to this dataset to find fits in reasonable proximity to the $\mathrm{bc} 1^{*}$ parameter set (Fits I-II, Table 6). Note that some values, including especially $\alpha_{\mathrm{s}, 0, \mathrm{X}}$, are poorly constrained by experiment and were given large tolerances during the fitting process. Figure 2 in Lee and Chan (2007) shows the decay of oleic acid in two particles, the smaller of which was chosen for modelling in this study. The exact particle size was not reported in the original publication and particle size has thus been used as a fit parameter. We have varied the particle diameter between $40-70 \mu \mathrm{m}$ along with the non-bracketed parameters in Fits I $\left(\mathrm{B}_{\alpha}\right.$ case) and II (B ${ }^{\text {rd }}$ regime) given in Table 6 . Both fits are in good agreement the experimental data, as shown in Fig. 6b.

The two fits shown here were calculated assuming a particle diameter of $40 \mu \mathrm{m}$ for the smaller particle, which is within the size range estimated by Lee and Chan (2007). Due to the large particle size in this dataset, the layer spacing scheme in KM-SUB had to be altered to achieve numerical convergence of the modelling result. From a total of 200 computed layers, 40 were chosen to form a narrowly resolved surface region. Each of these layers was attributed a depth of about 10 ozone monolayers $(4 \mathrm{~nm})$. The residual space was then equally distributed in depth among the 160 remaining layers. 
Table 6. Kinetic parameter sets for KM-SUB that represent possible fits to experimental data provided by Ziemann (2005), Lee and Chan (2007) and Hearn et al. (2005). bc1, bc1* and Fit I are obtained by adjusting $\alpha_{\mathrm{s}, 0, \mathrm{X}}$ while Fits II to IV are multi-parameter fits, obtained by least-squares fitting of modelled to experimental data. Even though Fits II and III do not exhibit limiting case behaviour, they can still be assigned as a bulk reaction limited by reaction and diffusion (reacto-diffusion limitation). Values that were fixed during the fitting procedures are marked with square brackets.

\begin{tabular}{|c|c|c|c|c|c|c|}
\hline Parameters & $\begin{array}{c}\mathrm{bc}^{\mathrm{a}} \\
\text { Ziemann }\end{array}$ & $\begin{array}{c}\text { bc1* } \\
\text { Ziemann }\end{array}$ & $\begin{array}{c}\text { Fit I } \\
\text { Lee and Chan }\end{array}$ & $\begin{array}{c}\text { Fit II } \\
\text { Lee and Chan }\end{array}$ & $\begin{array}{l}\text { Fit III } \\
\text { Hearn }\end{array}$ & $\begin{array}{l}\text { Fit IV } \\
\text { Hearn }\end{array}$ \\
\hline$k_{\mathrm{BR}}\left(\frac{\mathrm{cm}^{3}}{\mathrm{mols}}\right)$ & {$\left[1.70 \times 10^{-15}\right]$} & {$\left[1.70 \times 10^{-15}\right]$} & {$\left[1.70 \times 10^{-15}\right]$} & $2.52 \times 10^{-16}$ & $3.47 \times 10^{-17}$ & $1.72 \times 10^{-17}$ \\
\hline$k_{\mathrm{SLR}}\left(\frac{\mathrm{cm}^{2}}{\mathrm{mols}}\right)$ & {$\left[6.00 \times 10^{-12}\right]$} & {$\left[6.00 \times 10^{-12}\right]$} & {$\left[6.00 \times 10^{-12}\right]$} & {$\left[6.00 \times 10^{-12}\right]$} & {$\left[6.00 \times 10^{-12}\right]$} & $2.90 \times 10^{-12}$ \\
\hline$D_{\mathrm{b}, \mathrm{X}}\left(\frac{\mathrm{cm}^{2}}{\mathrm{~s}}\right)$ & {$\left[1.00 \times 10^{-5}\right]$} & {$\left[1.00 \times 10^{-5}\right]$} & {$\left[1.00 \times 10^{-5}\right]$} & {$\left[1.00 \times 10^{-5}\right]$} & {$\left[1.00 \times 10^{-5}\right]$} & {$\left[1.00 \times 10^{-5}\right]$} \\
\hline$D_{\mathrm{b}, \mathrm{Y}}\left(\frac{\mathrm{cm}^{2}}{\mathrm{~s}}\right)$ & {$\left[1.00 \times 10^{-10}\right]$} & {$\left[1.90 \times 10^{-7}\right]$} & {$\left[1.90 \times 10^{-7}\right]$} & {$\left[1.90 \times 10^{-7}\right]$} & {$\left[1.90 \times 10^{-7}\right]$} & {$\left[1.90 \times 10^{-7}\right]$} \\
\hline$H_{\mathrm{cp}, \mathrm{X}}\left(\frac{\mathrm{mol}}{\mathrm{cm}^{3} \mathrm{~atm}}\right)$ & {$\left[4.80 \times 10^{-4}\right]$} & {$\left[4.80 \times 10^{-4}\right]$} & {$\left[4.80 \times 10^{-4}\right]$} & $6.51 \times 10^{-5}$ & $8.81 \times 10^{-4}$ & $4.91 \times 10^{-5}$ \\
\hline$\tau_{\mathrm{d}, \mathrm{X}}(\mathrm{s})$ & {$\left[1.00 \times 10^{-2}\right]$} & {$\left[1.00 \times 10^{-8}\right]$} & {$\left[1.00 \times 10^{-8}\right]$} & {$\left[1.00 \times 10^{-8}\right]$} & {$\left[1.00 \times 10^{-8}\right]$} & $1.10 \times 10^{-4^{b}}$ \\
\hline$\alpha_{\mathrm{s}, 0, \mathrm{X}}(-)$ & $4.20 \times 10^{-4}$ & $4.61 \times 10^{-4}$ & $3.04 \times 10^{-4}$ & $4.18 \times 10^{-2}$ & $2.81 \times 10^{-2}$ & $3.08 \times 10^{-2}$ \\
\hline$D_{\mathrm{g}, \mathrm{X}}\left(\frac{\mathrm{cm}^{2}}{\mathrm{~s}}\right)$ & {$\left[1.4 \times 10^{-1}\right]$} & {$\left[1.4 \times 10^{-1}\right]$} & {$\left[1.4 \times 10^{-1}\right]$} & {$\left[1.4 \times 10^{-1}\right]$} & {$\left[1.4 \times 10^{-1}\right]$} & {$\left[1.4 \times 10^{-1}\right]$} \\
\hline \multicolumn{7}{|l|}{$10 \%$ reaction course } \\
\hline STLR & 0.310 & $4.63 \times 10^{-7}$ & $3.52 \times 10^{-7}$ & $1.37 \times 10^{-3}$ & $2.06 \times 10^{-4}$ & 0.966 \\
\hline $\mathrm{SR}$ & 0.082 & 0.079 & 0.031 & 0.905 & 0.951 & 0.996 \\
\hline MP & 0.999 & 0.999 & 0.965 & 0.483 & 0.744 & 0.999 \\
\hline \multicolumn{7}{|l|}{$50 \%$ reaction course } \\
\hline STLR & 0.259 & $3.61 \times 10^{-7}$ & $2.61 \times 10^{-7}$ & $9.00 \times 10^{-4}$ & $3.14 \times 10^{-4}$ & 0.964 \\
\hline $\mathrm{SR}$ & 0.056 & 0.108 & 0.044 & 0.928 & 0.969 & 0.998 \\
\hline MP & 0.999 & 0.999 & 0.966 & 0.482 & 0.7455 & 0.999 \\
\hline Regime/Limiting case & $\mathrm{SB}^{\alpha}$ & $\mathrm{B}_{\alpha}^{\mathrm{c}}$ & $\mathrm{B}_{\alpha}$ & $\mathrm{B}^{\mathrm{rd}}$ & $\mathrm{B}^{\mathrm{rd}}$ & $\mathrm{S}_{\mathrm{rx}}$ \\
\hline
\end{tabular}

a As provided by (Pfrang et al., 2010).

$\mathrm{b}$ This value implies formation of an intermediate at the particle surface.

c SR at $50 \%$ reaction course is slightly outside the numerical criterion for this assignment.

The consequences of using an insufficient number of layers, leading to non-resolved (step) gradients are briefly addressed in Appendix C.

Both Fit I and Fit II are consistent with the observed decay and could only be distinguished from one another in fit quality in the final stages of the reaction, for which no data are available. However, Fit I directly matches the $\mathrm{B}_{\alpha}$ assignment that was made for the dataset of Ziemann (2005), while Fit II would only match a nonlinear decay. Indeed, most previous observations of this system, which are summarised in the comprehensive review of Zahardis and Petrucci (2007), were generally nonlinear in time. This is an example of the logical error which arises when limiting case behaviour observed under one condition (small particles, high oxidant concentration) is assumed to apply elsewhere (very large particles, much lower oxidant concentration). We therefore continue with a more in-depth analysis of a dataset measured with smaller particles at high oxidant concentration that shows a pronounced nonlinearity and includes data to the very end of the reaction.

\subsection{Hearn et al. (2005) dataset}

A second multi-parameter fit was applied to the aerosol Chemical Ionization Mass Spectrometric measurements in Hearn et al. (2005) (650 nm diameter oleic acid particles reacting with $2.76 \times 10^{15} \mathrm{~cm}^{-3}$ ozone in an aerosol flow tube). As shown in Fig. 6c, the resulting fits exhibit behaviour indicative of the $\mathrm{B}^{\text {rd }}$ regime (bulk reaction limited by chemical reaction and/or bulk diffusion) and the $S_{r x}$ limiting case (surface reaction limited by chemical reaction), respectively. Although both Fit III and Fit IV resemble the experimental data reasonably when viewed on a linear scale, the logarithmic representation of Fig. 6d shows that Fit III deviates marginally from the data after $2.0 \mathrm{~s}$. This was already discussed by Hearn et al. for the traditional reacto-diffusive case $\mathrm{B}_{\text {trad }}^{\text {rd }}$, which is a subset of the $\mathrm{B}^{\text {rd }}$ regime. The $\mathrm{B}_{\text {trad }}^{\text {rd }}$ case has 
(a) bc1 ( $\mathrm{SB}^{\alpha}$ regime) to Ziemann

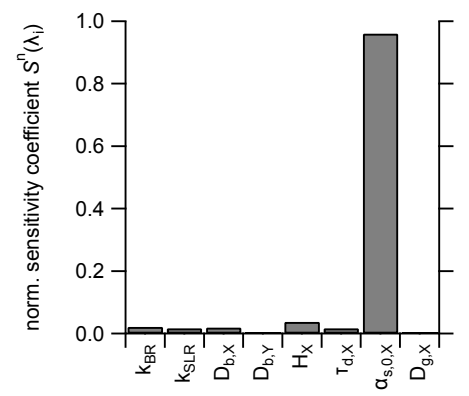

(d) Fit II ( $B^{\text {rd }}$ regime) to Lee and Chan

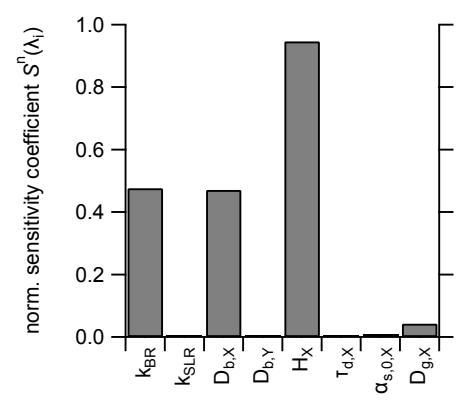

(b) bc $^{*}\left(\mathrm{~B}_{\alpha}\right.$ case $)$ to Ziemann

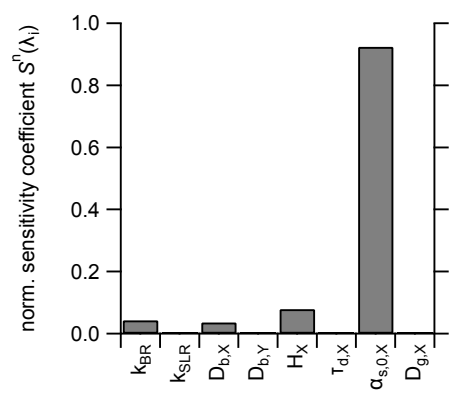

(e) Fit III ( $\mathrm{B}^{\text {rd }}$ regime) to Hearn et al.

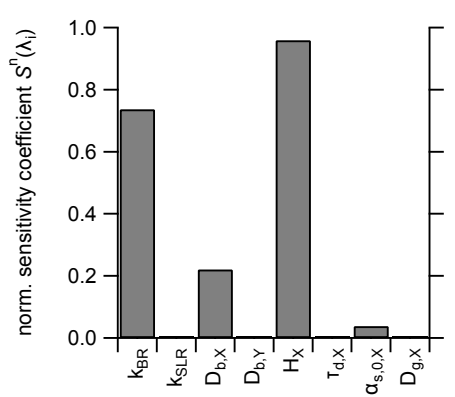

(c) Fit I ( $B_{\alpha}$ case) to Lee and Chan

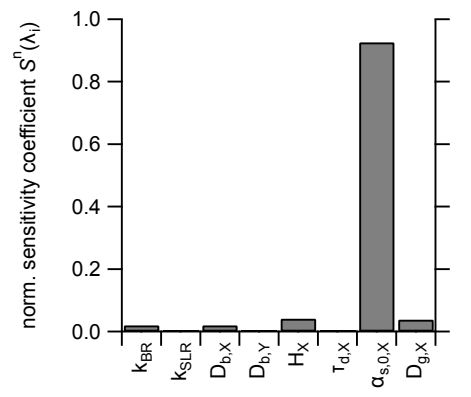

(f) Fit IV $\left(\mathrm{S}_{\mathrm{rx}}\right.$ case) to Hearn et al.

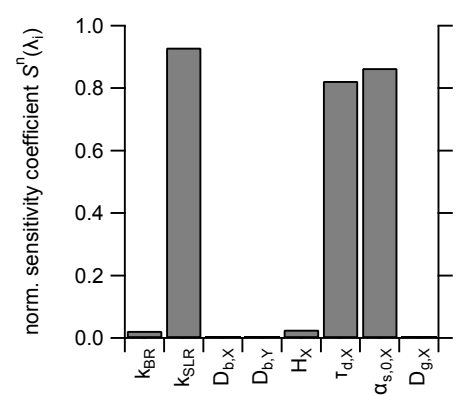

Fig. 7. Sensitivity profiles of parameter sets for a KM-SUB simulation of oleic acid-ozone. The parameter values used to generate these fits are shown in Table 6. Datasets are: (a) and (b), Ziemann (2005); (c) and (d), Lee and Chan (2007); (e) and (f), Hearn et al. (2005). These sensitivity tests corroborate the limiting case and regime assignments made in this study, and indicate that the $9: 1$ criterion is sufficient to separate limiting case behaviours. The sensitivity coefficients were determined via Morris' Elementary Effects method for global sensitivity analysis (Morris, 1991) as recommended by Saltelli et al. (2008).

a quadratic-like functional form in $N_{\mathrm{Y}}(t)$ that is not able to fit the experimentally observed mono-exponential decay. In contrast to the "ideal" $B_{\text {trad }}^{\text {rd }}$ case, Fit III does not show a true quadratic decay shape and lies significantly closer to the experimental data compared to the fit shown in Fig. 2 of Hearn et al. (2005). This improved fit arises because Fit III does not exactly match the $\mathrm{B}_{\text {trad }}^{\text {rd }}$ scenario and its kinetic behaviour changes towards $\mathrm{B}_{\mathrm{rx}}$ as the reaction proceeds.

A rather different picture of the internal structure of the aerosol particle is provided with Fit IV, showing an excellent fit to the experimental data in reasonable proximity to the original bc1 parameter set of Pfrang et al. (2010). This fullysaturated surface reaction is consistent with the conclusion of Hearn et al. (2005), who suggested that the reaction occurs exclusively on the particle surface as a result of a quasismectic structure of the uppermost oleic acid layer that is impenetrable by ozone due to slow diffusion and fast reaction.

We note that the surface reaction behaviour in Fit IV is only achieved using a $\tau_{\mathrm{d}, \mathrm{X}}$ which significantly exceeds the values inferred from molecular dynamics simulations as discussed in Sect. 6.2 above. Such a value would be acceptable only if a long-lived intermediate was formed at the particle surface (as discussed in Shiraiwa et al. (2011b) for $\mathrm{PAH}+\mathrm{O}_{3}$ ).

Both Fit III and Fit IV are in reasonable agreement with the single experimental decay in Fig. 6. However, further ex- perimental results of Hearn et al. with differently sized particles indicate that the initial reaction rate scales inversely with the particle radius $\left(S^{n}\left(r_{\mathrm{p}}\right)=-1\right)$, which is typical for systems that are limited by a surface-related process such as $\mathrm{S}_{\mathrm{rx}}, \mathrm{B}_{\alpha}$ or $\mathrm{B}_{\text {trad }}^{\mathrm{rd}}$ (see Table 4). A more detailed discussion of the size-dependent data can be found in Appendix E.

\subsection{Sensitivity profiles of displayed limiting cases}

As discussed in Sect. 4.3, we recommend sensitivity analysis to confirm that the numerical criteria chosen result in distinct and well-behaved limiting cases. Figure 7 shows the sensitivity profiles of the six parameter sets found for the oleic acidozone system. In each case, the assignment is supported by the sensitivity analysis. Sensitivity coefficients are given at $10 \%$ reaction course as this not only avoids the initial, highly transient behaviour which is expected as the surface and first bulk layers come into equilibrium with the gas phase, but also minimises the error associated with neglecting reaction products in the depth-resolved model.

The interpretation of the fits to Ziemann (2005) data, panels a and b of Fig. 7 is relatively straightforward. As expected from Table 3 , these fits are only sensitive to the accommodation coefficient $\alpha_{\mathrm{s}, 0, \mathrm{X}}$. Indeed, in panel a, only $\alpha_{\mathrm{s}, 0, \mathrm{X}}$ is indicated as a direct control on the result of the calculation, in accordance with the accommodation regime $\left(\mathrm{SB}^{\alpha}\right)$. In panel 
$\mathrm{b}$, the sensitivity to $\alpha_{\mathrm{s}, 0, \mathrm{X}}$ remains high while some minor dependence on parameters related to bulk reaction $\left(H_{\mathrm{cp}, \mathrm{X}}, k_{\mathrm{BR}}\right.$, $\left.D_{\mathrm{b}, \mathrm{X}}\right)$ is observed, both in agreement with the assignment as $\mathrm{B}_{\alpha}$ limiting case (bulk reactions limited by accommodation).

Panels $\mathrm{c}$ and $\mathrm{d}$ show sensitivity analyses of fits to the Lee and Chan (2007) data and reveal very typical behaviour for the $\mathrm{B}_{\alpha}$ case and the $\mathrm{B}^{\mathrm{rd}}$ regime, respectively. While Fit $\mathrm{I}$ in panel $\mathrm{c}$ is completely governed by the $\alpha_{\mathrm{s}, 0, \mathrm{X}}$ parameter, Fit II in panel $d$ shows the traditional reacto-diffusive behaviour with a balanced sensitivity towards the reaction and diffusion process. In both cases, the large particle radius leads to a slight influence of gas-phase diffusion as indicated by sensitivity to $D_{\mathrm{g}, \mathrm{X}}$.

The interpretation of the fits to Hearn et al. (2005) data, panels e and f of Fig. 7 also confirms our assignments. In panel $\mathrm{e}$, the parameters indicate a mixture of bulk reaction and bulk diffusion limiting cases ( $\mathrm{B}^{\text {rd }}$ regime). Unlike Fit II in panel $\mathrm{d}$, this case does not coincide with the traditional $\mathrm{B}_{\text {trad }}^{\text {rd }}$ case, as it shows a slight predominance towards reaction limitation and thus $\mathrm{B}_{\mathrm{rx}}$ behaviour. This example demonstrates the breadth of possible behaviours for cases that do not fall into a distinct limiting case but rather exhibit regime behaviour. In panel $f$, the surface reaction rate coefficient $k_{\mathrm{SLR}}$ as well as the parameters determining the surface coverage $\left(\tau_{\mathrm{d}, \mathrm{X}}\right.$ and $\left.\alpha_{\mathrm{s}, 0}\right)$ are influential. Thus, $\mathrm{S}_{\mathrm{rx}}$ behaviour was correctly assigned.

In general, sensitivity coefficients were not observed to vary significantly over time once a quasi-stationary state of transport and reaction was reached. In the event that behaviour is not consistent throughout the reaction, a change in regime or limiting case behaviour can be detected by a change in classification parameters and the sensitivity coefficients follow accordingly. For example, classification parameters for Fit III (Table 6) show an increase in mixing parameter $\mathrm{BMP}_{\mathrm{XY}}$ over time, indicating a smooth transition from $\mathrm{B}^{\text {rd }}$ regime towards $\mathrm{B}_{\mathrm{rx}}$ limiting case behaviour. This is accompanied by a decrease in sensitivity towards the bulk diffusion coefficient $D_{\mathrm{b}, \mathrm{X}}$ from $S^{n}\left(D_{\mathrm{b}, \mathrm{X}}\right)=0.22$ at $10 \%$ reaction course to 0.16 at $50 \%$ reaction course and 0.04 at $90 \%$ reaction course.

In interpreting these sensitivity analyses, a low sensitivity does not necessarily mean that a process related to that parameter is unimportant, only that modest changes in that parameter do not have a strong influence on the model result. This could be the case if a parameter is obviated (e.g. the Henry's law constant in a system which reacts exclusively at the surface, in which case it could take on any value) or if a process is saturated (e.g. the reaction rate coefficient in an accommodation-limited case, for which modest changes in $k_{\mathrm{BR}}$ would not matter as the reaction would remain "fast" compared to the accommodation process). Overall, the simple 9: 1 numerical criteria proposed in Sect. 4.2 were sufficient for this system, but should be revisited for each new chemical system to ensure that limiting cases and regimes are well-behaved (that is, influenced by only one or two processes, respectively).

\subsection{Conclusions from the case study}

In summary, analysis of three literature datasets of the oleic acid-ozone reaction system led to six different sets of kinetic parameters for the applied kinetic model KM-SUB. The proposed classification scheme was applied to these fits, leading to assignments of limiting cases or regimes. However, underlying kinetic parameters could not be determined uniquely and no final limiting case assignment could be made. This is, however not the result of a deficiency in the classification scheme. Rather, it highlights the inherent complexity of experimental kinetics and the fitting process necessary to infer kinetic parameters from experimental data. Parameters which are not among the limiting parameters of the reaction system (cf. Table 3 and Fig. 7) do not directly influence the reaction rate and are thus poorly constrained by experiments. Single measurements in one kinetic regime can usually only determine one (or a few) parameter(s), and put constraints on others.

Consequently, none of the example parameter sets given here was able to fit all three experimental datasets. A parameter set which fully represents the underlying kinetic parameters in the oleic acid-ozone system will thus require further experimental and theoretical studies in which multiple datasets are simultaneously fitted (a global fit). These datasets should ideally be obtained under vastly differing conditions (reaction time, particle size and oxidant concentration), thereby changing the kinetic regime and providing constraints on a wider variety of kinetic parameters.

\section{Summary and conclusions}

The development of depth-resolved models for aerosol chemistry has prompted the more sophisticated, systematic classification of the kinetic behaviour of aerosol particles proposed here. The set of limiting cases and associated symbols proposed above should allow a more complete and more intuitive discussion of aerosol particle behaviour, especially in systems which exhibit stiff coupling of physical and/or chemical processes. In particular, the more complete treatment of mass transfer limitation presented in this study not only allows for analysis of such systems, but may also assist in interpreting and reconciling previous studies.

Limiting case or kinetic regime assignments facilitate the interpretation of experimental data since, in principle, only the rate limiting process(es) have to be considered when calculating or analysing reactive uptake. During an experimental study, results can be compared to the characteristic behaviours described in Sect. 5 which may provide insight into the kinetic behaviour of aerosol particles. If the experimental results match a profile of a limiting case, the predicted 
sensitivity of the assigned case to experimental conditions may be useful in guiding follow-up experiments.

As outlined above, a single chemical reaction system can exhibit different kinetic behaviours depending on reaction conditions such as concentration levels and particle sizes. The classification scheme proposed here provides a means of characterising a specific reaction system under specific conditions, but the underlying parameters which drive the physical and chemical behaviour remain the most valuable information which models can extract from experimental data. This is particularly important for the extrapolation of laboratory results to atmospherically relevant conditions, a task which demands a well-constrained parameter set to provide reliable results. Therefore, we emphasise the need for experiments at different time scales, particle sizes and reactant concentrations, to provide enough constraints for accurate determination of fundamental kinetic parameters. In light of the breakdown of the exposure metric (oxidant concentration $\times$ time) for some aerosol behaviours, we recommend that studies which use the exposure metric should also provide independent concentration and time data for future reanalysis.

Multi-parameter fitting of three different datasets for the benchmark system of oleic acid reacting with ozone has shown that the available data can be represented by different sets of kinetic parameters that do not correspond to a single kinetic behaviour (regime or limiting case). Using only one dataset at a time for the fitting of several kinetic parameters resulted in an under-determined system.

We conclude that for a well-constrained kinetic parameter set, several datasets should be taken into account simultaneously to provide a sufficiently broad set of constraints for the fitting result. These sets must include a wide range of experimental conditions, since non-limiting parameters are only poorly constrained by experimental data. Multiparameter fitting to multiple datasets for extraction of kinetic parameters would therefore be of general importance for modelling of multiphase chemistry, but requires a significantly higher technical effort. The prospects and challenges of multi-dimensional fitting to elucidate the kinetic parameters of aerosol reaction systems will thus be addressed in detail in a follow-up study, building on the classification framework provided here.

\section{Appendix B}

\section{Additional regimes}

In addition to the reaction-diffusion and mass transfer regimes used throughout this work, there are many other combinations of limiting cases to form regimes which are possible. Sorting by mixing parameter MP leads to the distinction in Fig. S1a, the diffusion regime and the reactionaccommodation regime. This separation is less common than that shown in Fig. 3a for analysis of chemical reactivity. The typical example of a system in the reaction-accommodation regime arises when a particle is well-mixed and neither saturated nor starved on trace gas X, indicated by SSR and/or $\mathrm{BSR} \approx 0.5$. Here, reaction and accommodation occur on similar time scales and are thus closely coupled. Another possibility is shown in Fig. S1b, in which the separation is made between chemical rate limitation ("reaction regime") and all other possibilities ("mass transport regime"). We view the mass transport regime (not to be confused with the mass transfer regime $\mathrm{SB}^{\mathrm{mt}}$ ) in Fig. S1b as too broad to be useful, as systems lying in this regime may encompass every limitation on chemical reaction rate except the actual rate coefficient.

\section{Appendix C}

\section{Strong bulk concentration gradients not equivalent to diffusion limitation}

As already described in Sect. 2.2, the reaction-diffusion regime encompasses all cases limited by chemical reaction and/or bulk diffusion and the traditional reacto-diffusive case within this regime, $\mathrm{B}_{\text {trad }}^{\text {rd }}$, occurs when $\mathrm{STLR} \approx 0, \mathrm{BSR} \approx 1$, $\mathrm{BMP}_{\mathrm{X}} \approx 0$ and $\mathrm{BMPY} \approx 1$. In this situation, the surface and first subsurface bulk layer are saturated with $\mathrm{X}$ and the short reacto-diffusive length of $X$ limits the reaction volume and thus reactive uptake. Because reaction and diffusion of $\mathrm{X}$ are inherently coupled in the $\mathrm{B}_{\text {trad }}^{\text {rd }}$ case, this case does not exhibit $\mathrm{B}_{\mathrm{bd}}$ behaviour even though it shows a strong gradient in $\mathrm{X}$. This would violate the definition of single-process limitation for limiting cases given in Sect. 2.1.

In addition to the $\mathrm{B}_{\text {trad }}^{\text {rd }}$ case, another behaviour can also be observed when $\mathrm{BMPX}_{\mathrm{X}} \approx 0, \mathrm{BMPY}_{\mathrm{Y}} \approx 1, \mathrm{SSR} \approx 1$, but $\mathrm{BSR} \approx 0$. Here, the surface is saturated with $\mathrm{X}$ but the transfer from surface to bulk is inefficient compared to reaction in the bulk. Since $B S R \approx 0$ in this situation, this case is correctly assigned as a $\mathrm{B}_{\alpha}$ case, and has a behaviour which is consistent with the archetypal $\mathrm{B}_{\alpha}$ case described in Sect. 5.1. We will distinguish this surface to bulk transfer-limited case from the gas to surface transfer-limited case by referring to each as $\mathrm{B}_{\alpha, \mathrm{s} \rightarrow \mathrm{b}}$ and $\mathrm{B}_{\alpha, \mathrm{g} \rightarrow \mathrm{s}}$, respectively.

Typically, the values of SSR and BSR are expected to be similar (for an overview of the relationship between SSR and BSR for different limiting cases and regimes, see Table S3). As suggested by the name "surface to bulk transfer-limited", a discrepancy between SSR and BSR arises in the $\mathrm{B}_{\alpha, s \rightarrow \mathrm{b}}$ case. This situation depends crucially on the layer spacing in the model. Such a discrepancy between SSR and BSR could arise when the reacto-diffusive length is so short that it falls below layer spacing, which is often constrained to be one molecular length (e.g. a monolayer of Y) or larger. In such a situation, the assumption of internally well-mixed model layers is violated and the quasi-static surface layer acts as a diffusional bottleneck that has to be surpassed before bulk 
Table A1. List of symbols and abbreviations.

\begin{tabular}{|c|c|c|}
\hline Symbol & Meaning & SI Unit \\
\hline$\alpha_{\mathrm{b}, \mathrm{X}}$ & bulk accommodation coefficient of X & \\
\hline$\alpha_{\mathrm{s}, \mathrm{X}}$ & surface accommodation coefficient of X & \\
\hline$\alpha_{\mathrm{s}, 0, \mathrm{X}}$ & surface accommodation coefficient of $\mathrm{X}$ on an adsorbate-free surface & \\
\hline$\gamma_{\mathrm{X}}$ & uptake coefficient of X (normalised by gas kinetic flux of surface collisions) & \\
\hline$\gamma_{\mathrm{eff}, \mathrm{X}}$ & effective uptake coefficient of $X$ (normalised by average gas kinetic flux) & \\
\hline$\delta_{Y}$ & effective molecular length of Y & $\mathrm{m}$ \\
\hline$\theta_{\mathrm{S}, \mathrm{X}}$ & surface coverage by $\mathrm{X}$ (sorption layer) & \\
\hline$\theta_{\mathrm{S}, \mathrm{max}, \mathrm{X}}$ & maximum surface coverage by $\mathrm{X}$ (sorption layer) & \\
\hline$\theta_{\mathrm{S}, \mathrm{sat}, \mathrm{X}}$ & saturation surface coverage by $\mathrm{X}$ (sorption layer) & \\
\hline$\lambda_{i}$ & kinetic input parameter $i$ & \\
\hline$\lambda x$ & mean free path of $\mathrm{X}$ in the gas phase & $\mathrm{m}$ \\
\hline$\tau_{\mathrm{d}, \mathrm{X}}$ & desorption lifetime of $\mathrm{X}$ & $\mathrm{s}$ \\
\hline$\omega_{\mathrm{X}}$ & mean thermal velocity of $X$ & $\mathrm{~ms}^{-1}$ \\
\hline bc1 & base case 1 input parameter set & \\
\hline $\mathrm{bc1} 1^{*}$ & modified base case 1 input parameter set & \\
\hline $\mathrm{BMP}_{\mathrm{X}}$ & mixing parameter for bulk diffusion of $\mathrm{X}$ (bulk reaction) & \\
\hline $\mathrm{BMP}_{\mathrm{Y}}$ & mixing parameter for bulk diffusion of $\mathrm{Y}$ (bulk reaction) & \\
\hline $\mathrm{BMP}_{\mathrm{XY}}$ & joint mixing parameter for bulk diffusion of $\mathrm{X}$ and $\mathrm{Y}$ (bulk reaction) & \\
\hline BSR & bulk saturation ratio & \\
\hline$C_{\mathrm{g}, \mathrm{X}}$ & gas-phase diffusion correction factor for $\mathrm{X}$ and mixing parameter for gas phase $\mathrm{X}$ & \\
\hline$D_{\mathrm{b}, \mathrm{X}}$ & particle bulk diffusion coefficient of $X$ & $\mathrm{~m}^{2} \mathrm{~s}^{-1}$ \\
\hline$D_{\mathrm{g}, \mathrm{X}}$ & gas-phase diffusion coefficient of $\mathrm{X}$ & $\mathrm{m}^{2} \mathrm{~s}^{-1}$ \\
\hline$H_{\mathrm{cp}, \mathrm{X}}$ & Henry's law coefficient of X & $\mathrm{molm}^{-3} \mathrm{~Pa}^{-1}$ \\
\hline$k_{\mathrm{a}}$ & first-order adsorption rate coefficient of $\mathrm{X}$ & $\mathrm{ms}^{-1}$ \\
\hline$k_{\mathrm{d}}$ & first-order desorption rate coefficient of $\mathrm{X}$ & $\mathrm{s}^{-1}$ \\
\hline$k_{\mathrm{BR}}$ & second-order rate coefficient for bulk reactions & $\mathrm{m}^{3} \mathrm{~s}^{-1}$ \\
\hline$k_{\mathrm{SLR}}$ & second-order rate coefficient for surface layer reactions & $\mathrm{m}^{2} \mathrm{~s}^{-1}$ \\
\hline$K_{\text {ads, } \mathrm{X}}$ & adsorption equilibrium constant of $\mathrm{X}$ & $\mathrm{m}^{3}$ \\
\hline$K_{\mathrm{sol}, \mathrm{cc}, \mathrm{X}}$ & dimensionless solubility or gas-particle partitioning coefficient of $\mathrm{X}$ & \\
\hline$K n_{\mathrm{X}}$ & Knudsen number for $\mathrm{X}$ & \\
\hline$l_{\mathrm{rd}, \mathrm{X}}$ & reacto-diffusive length of $\mathrm{X}$ in $\mathrm{Y}$ & $\mathrm{m}$ \\
\hline$L_{k}$ & loss rate upon bulk reaction in layer $k$ & $s^{-1}$ \\
\hline$L_{\mathrm{S}}$ & loss rate upon surface reaction & $s^{-1}$ \\
\hline$L_{\text {tot }}$ & total loss rate (of surface and bulk reaction) & $\mathrm{s}^{-1}$ \\
\hline SR & saturation ratio & \\
\hline$n$ & number of bulk layers in discretized representation of the particle & \\
\hline$N_{\mathrm{Y}}$ & number of molecules of Y left in the aerosol particle & \\
\hline$r_{\mathrm{p}}$ & particle radius & $\mathrm{m}$ \\
\hline$S\left(\lambda_{i}\right)$ & model sensitivity towards $\lambda_{i}$ & \\
\hline$S^{n}\left(\lambda_{i}\right)$ & normalised model sensitivity towards $\lambda_{i}$ & \\
\hline $\mathrm{SMP}_{\mathrm{Y}}$ & mixing parameter for bulk mixing of Y (surface reaction) & \\
\hline SR & saturation ratio & \\
\hline SSR & surface saturation satio & \\
\hline STLR & surface to total loss rate ratio & \\
\hline$t$ & time & s \\
\hline$T$ & temperature & $\mathrm{K}$ \\
\hline$V_{k}$ & volume of layer $k$ & $\mathrm{~m}^{3}$ \\
\hline $\mathrm{X}$ & trace gas species & \\
\hline$[\mathrm{X}]_{\mathrm{eff}}$ & effective bulk concentration of $\mathrm{X}$ experienced by reacting $\mathrm{Y}$ & $\mathrm{m}^{-3}$ \\
\hline$[\mathrm{X}]_{\mathrm{g}}$ & gas-phase number concentration of $\mathrm{X}$ & $m^{-3}$ \\
\hline$[\mathrm{X}]_{\mathrm{gs}}$ & near-surface gas-phase number concentration of $\mathrm{X}$ & $\mathrm{m}^{-3}$ \\
\hline$[\mathrm{X}]_{\mathrm{s}}$ & surface number concentration of X (sorption layer) & $\mathrm{m}^{-2}$ \\
\hline$[\mathrm{X}]_{\mathrm{ss}}$ & subsurface number concentration of X (quasi-static surface layer) & $\mathrm{m}^{-2}$ \\
\hline$[\mathrm{X}]_{\mathrm{s}, \max }$ & maximum surface number concentration of X (sorption layer) & $\mathrm{m}^{-2}$ \\
\hline$[\mathrm{X}]_{\mathrm{s}, \mathrm{sat}}$ & saturation surface number concentration of $\mathrm{X}$ (sorption layer) & $\mathrm{m}^{-2}$ \\
\hline$[\mathrm{X}]_{\mathrm{b}}$ & particle bulk number concentration of $\mathrm{X}$ & $\mathrm{m}^{-3}$ \\
\hline$[\mathrm{X}]_{\mathrm{b} k}$ & number concentration of $\mathrm{X}$ in $k$-th bulk layer & $\mathrm{m}^{-3}$ \\
\hline$[\mathrm{X}]_{\mathrm{b}, \mathrm{sat}}$ & saturation particle bulk number concentration of $\mathrm{X}$ & $\mathrm{m}^{-3}$ \\
\hline $\mathrm{Y}$ & bulk material species & \\
\hline$Y_{\text {model }}$ & model output & \\
\hline
\end{tabular}


reaction can occur. This effectively decouples the reaction and diffusion process. However, the treatment of competing reaction and diffusion at the molecular level might not be well-represented by the kinetic model applied here and thus lies beyond the scope of this paper.

A more intuitive example for a $\mathrm{B}_{\alpha, \mathrm{s} \rightarrow \mathrm{b}}$ case is a particle that is coated by an inert and only slowly penetrable shell such as a monolayer of saturated fatty acids (Rouvière and Ammann, 2010).

\section{Appendix D}

\section{Idealised limiting cases}

The complete list of input parameters and experimental conditions for the idealised limiting cases employed in Sect. 5 is given in Tables S2 and S3. As in all other calculations in this work, it was assumed that all kinetic (e.g. $k_{\mathrm{BR}}, D_{\mathrm{b}, \mathrm{X}}$, $\left.D_{\mathrm{b}, \mathrm{Y}}\right)$ and environmental (e.g. $\left.[\mathrm{X}]_{\mathrm{g}}, r_{\mathrm{p}}, T\right)$ parameters remain constant as the reaction proceeds. Single-process limitation was ensured by disabling competing processes $\left(\lambda_{i}=0\right)$ and increasing the speed of non-limiting processes $\left(\lambda_{i}=1\right)$. To achieve similar uptake coefficients, the kinetic parameters were tuned so that an aerosol particle with $100 \mathrm{~nm}$ radius was processed in $\sim 100 \mathrm{~s}$. The parameter sets themselves are thus not based on physically correct scenarios, but represent systems which exhibit pure, single-process limiting behaviour.

\section{Appendix E}

\section{Particle size-dependent data}

Hearn et al. (2005) use initial loss rates measured at different particle sizes to further narrow down the kinetic limiting behaviour of the oleic acid-ozone reaction system. A model system's response to changes in particle size can be inferred by means of sensitivity analysis, which was conducted for Fits III and IV of Fig. 6c, d. Fit IV was found to match the experimentally observed inverse response of reaction rate to particle size $\left(S^{n}\left(r_{\mathrm{p}}\right)=-0.99\right)$, whereas Fit III shows rather an inverse root dependence $\left(S^{n}\left(r_{\mathrm{p}}\right)=-0.51\right)$. Thus, and in agreement with the original study of Hearn et al. (2005), we conclude that $S_{\mathrm{rx}}$ is the only single limiting case that fits the experimental observations of both decay shape and scaling of initial reaction rate with particle size. However, a behaviour which mixes the characteristics of more than one limiting case might also fit the data well, even though the limiting cases which it most closely resembles would fail individually. The Fit III parameter set presented here follows this logic by mixing the behaviours of $\mathrm{B}_{\text {trad }}^{\mathrm{rd}}$ and $\mathrm{B}_{\mathrm{rx}}$ to adequately represent both the near-exponential decay of $N_{\mathrm{Y}}$ as a function of time $\left(\mathrm{B}_{\mathrm{rx}}\right)$ and the scaling of the initial decay rate with particle radius $\left(\mathrm{B}_{\text {trad }}^{\text {rd }}\right)$. Although the agreement of Fit III with the experimental $N_{\mathrm{Y}}(t)$ and $S^{n}\left(r_{\mathrm{p}}\right)$ is not as good as that of Fit
IV, both are in reasonable proximity to experimentally measured values. This opens up another possibility for modelling of the oleic acid-ozone system that has yet to be proven by a well-fitting kinetic parameter set.

\section{Supplementary material related to this article is available online at: http://www.atmos-chem-phys.net/13/ 6663/2013/acp-13-6663-2013-supplement.pdf.}

Acknowledgements. T. Berkemeier acknowledges support from the European Union Lifelong Learning Programme. A. J. Huisman was supported by the United States National Science Foundation under award no. IRFP 1006117 and by ETH Zürich. M. Ammann appreciated support by the Swiss National Science Foundation (grant no. 130175). M. Shiraiwa is supported by the Japan Society for the Promotion of Science (JSPS) Postdoctoral Fellowship for Research Abroad and the EU project PEGASOS (grant no. 265148). Any opinions, findings, and conclusions or recommendations expressed in this material are those of the authors and do not necessarily reflect the views of the US National Science Foundation. T. Berkemeier and A. J. Huisman thank U. Krieger and T. Peter for their support and for many useful conversations. T. Berkemeier would like to thank P. Ziemann, G. Smith, C. Chan and A. Lee for providing original datasets.

The service charges for this open access publication have been covered by the Max Planck Society.

Edited by: V. F. McNeill

\section{References}

Abbatt, J. P. D., Lee, A. K. Y., and Thornton, J. A.: Quantifying trace gas uptake to tropospheric aerosol: recent advances and remaining challenges, Chem. Soc. Rev., 41, 6555-6581, doi:10.1039/C2CS35052A, 2012.

Ammann, M., Rossler, E., Strekowski, R., and George, C.: Nitrogen dioxide multiphase chemistry: uptake kinetics on aqueous solutions containing phenolic compounds, Phys. Chem. Chem. Phys., 7, 2513-2518, doi:10.1039/B501808K, 2005.

Bates, D. V.: Detection of chronic respiratory bronchiolitis in oxidant-exposed populations: analogy to tobacco smoke exposure, Environ. Health Pers., 101, 217-218, available at: http: //www.ncbi.nlm.nih.gov/pmc/articles/PMC1519706/, 1993.

Behr, P., Morris, J. R., Antman, M. D., Ringeisen, B. R., Splan, J. R., and Nathanson, G. M.: Reaction and desorption of $\mathrm{HCl}$ and $\mathrm{HBr}$ following collisions with supercooled sulfuric acid, Geophys. Res. Lett., 28, 1961-1964, doi:10.1029/2000GL012716, 2001.

Behr, P., Scharfenort, U., Ataya, K., and Zellner, R.: Dynamics and mass accommodation of $\mathrm{HCl}$ molecules on sulfuric acid-water surfaces, Phys. Chem. Chem. Phys., 11, 8048-8055, doi:10.1039/B904629A, 2009.

Cariboni, J., Gatelli, D., Liska, R., and Saltelli, A.: The role of sensitivity analysis in ecological modelling, Ecol. Model., 203, 167182, doi:10.1016/j.ecolmodel.2005.10.045, 2007. 
Carslaw, K. S., Boucher, O., Spracklen, D. V., Mann, G. W., Rae, J. G. L., Woodward, S. and Kulmala, M.: A review of natural aerosol interactions and feedbacks within the Earth system, Atmos. Chem. Phys., 10, 1701-1737, doi:10.5194/acp-10-17012010, 2010.

Crowley, J. N., Ammann, M., Cox, R. A., Hynes, R. G., Jenkin, M. E., Mellouki, A., Rossi, M. J., Troe, J., and Wallington, T. J.: Evaluated kinetic and photochemical data for atmospheric chemistry: Volume $\mathrm{V}$ - heterogeneous reactions on solid substrates, Atmos. Chem. Phys., 10, 9059-9223, doi:10.5194/acp-10-9059-2010, 2010.

Danckwerts, P. V.: Absorption by simultaneous diffusion and chemical reaction into particles of various shapes and into falling drops, Trans. Faraday Soc., 47, 1014-1023, doi:10.1039/TF9514701014, 1951.

Davidovits, P., Hu, J. H., Worsnop, D. R., Zahniser, M. S., and Kolb, C. E.: Entry of gas molecules into liquids, Faraday Discuss., 100, 65-81, doi:10.1039/FD9950000065, 1995.

Davidovits, P., Kolb, C. E., Williams, L. R., Jayne, J. T., and Worsnop, D. R.: Mass accommodation and chemical reactions at gas-liquid interfaces, Chem. Rev., 106, 1323-1354, doi:10.1021/cr040366k, 2006.

Deiber, G., George, Ch., Le Calvé, S., Schweitzer, F., and Mirabel, Ph.: Uptake study of $\mathrm{ClONO}_{2}$ and $\mathrm{BrONO}_{2}$ by Halide containing droplets, Atmos. Chem. Phys., 4, 1291-1299, doi:10.5194/acp-4-1291-2004, 2004.

Donaldson, D. J., Ravishankara, A. R., and Hanson, D. R.: Detailed Study of $\mathrm{HOCl}+\mathrm{HCl} \rightarrow \mathrm{C}_{1} 2+\mathrm{H}_{2} \mathrm{O}$ in Sulfuric Acid, J. Phys. Chem. A, 101, 4717-4725, doi:10.1021/jp9633153, 1997.

Dunker, A. M.: The decoupled direct method for calculating sensitivity coefficients in chemical kinetics, J. Chem. Phys., 81, 23852393, doi:10.1063/1.447938, 1984.

George, I. J., Matthews, P. S., Brooks, B., Goddard, A., Whalley, L. K., Baeza-Romero, M. T., and Heard, D. E.: Heterogeneous Uptake of $\mathrm{HO}_{2}$ Radicals onto Atmospheric Aerosols, abstract A43D-0186, presented at Fall Meeting, AGU, San Francisco, Calif., 5-9 December, 2011.

Hallquist, M., Wenger, J. C., Baltensperger, U., Rudich, Y., Simpson, D., Claeys, M., Dommen, J., Donahue, N. M., George, C., Goldstein, A. H., Hamilton, J. F., Herrmann, H., Hoffmann, T., Iinuma, Y., Jang, M., Jenkin, M. E., Jimenez, J. L., KiendlerScharr, A., Maenhaut, W., McFiggans, G., Mentel, Th. F., Monod, A., Prévôt, A. S. H., Seinfeld, J. H., Surratt, J. D., Szmigielski, R., and Wildt, J.: The formation, properties and impact of secondary organic aerosol: current and emerging issues, Atmos. Chem. Phys., 9, 5155-5236, doi:10.5194/acp-9-51552009, 2009.

Hanson, D. R. and Lovejoy, E. R.: Heterogeneous reactions in liquid sulfuric acid: $\mathrm{HOCl}+\mathrm{HCl}$ as a model system, J. Phys. Chem.US, 100, 6397-6405, doi:10.1021/jp953250o, 1996.

Hanson, D. R., Ravishankara, A. R., and Solomon, S.: Heterogeneous reactions in sulfuric acid aerosols: a framework for model calculations, J. Geophys. Res., 99, 3615-3629, doi:10.1029/93JD02932, 1994.

Heal, M. R., Kumar, P. and Harrison, R. M.: Particles, air quality, policy and health., Chem. Soc. Rev., 41, 6606-6630, doi:10.1039/c2cs35076a, 2012.

Hearn, J. D., Lovett, A. J., and Smith, G. D.: Ozonolysis of oleic acid particles: evidence for a surface reaction and secondary reactions involving Criegee intermediates, Phys. Chem. Chem. Phys., 7, 501-511, doi:10.1039/B414472D, 2005.

Hu, J. H., Shi, Q., Davidovits, P., Worsnop, D. R., Zahniser, M. S., and Kolb, C. E.: Reactive uptake of $\mathrm{Cl}_{2}(\mathrm{~g})$ and $\mathrm{Br}_{2}(\mathrm{~g})$ by aqueous surfaces as a function of $\mathrm{Br}^{-}$and $\mathrm{I}^{-}$ion concentration: the effect of chemical reaction at the interface, J. Phys. Chem., 99, 87688776, doi:10.1021/j100021a050, 1995.

IPCC: Climate Change 2007: The Physical Science Basis, Contribution of Working Group I to the Fourth Assessment Report of the Intergovernmental Panel on Climate Change, Cambridge University Press, Cambridge, United Kingdom and New York, NY, USA, 2007.

Jakab, G. J., Spannhake, E. W., Canning, B. J., Kleeberger, S. R., and Gilmour, M. I.: The effects of ozone on immune function, Environ. Health Pers., 103, 77-89, available at: http://www.ncbi. nlm.nih.gov/pmc/articles/PMC1518840/, 1995.

Kanakidou, M., Seinfeld, J. H., Pandis, S. N., Barnes, I., Dentener, F. J., Facchini, M. C., Van Dingenen, R., Ervens, B., Nenes, A., Nielsen, C. J., Swietlicki, E., Putaud, J. P., Balkanski, Y., Fuzzi, S., Horth, J., Moortgat, G. K., Winterhalter, R., Myhre, C. E. L., Tsigaridis, K., Vignati, E., Stephanou, E. G., and Wilson, J.: Organic aerosol and global climate modelling: a review, Atmos. Chem. Phys., 5, 1053-1123, doi:10.5194/acp-51053-2005, 2005.

Knipping, E. M. and Dabdub, D.: Modeling $\mathrm{Cl}_{2}$ formation from aqueous $\mathrm{NaCl}$ particles: Evidence for interfacial reactions and importance of $\mathrm{Cl}_{2}$ decomposition in alkaline solution, J. Geophys. Res., 107, 4360, doi:10.1029/2001JD000867, 2002.

Knipping, E. M., Lakin, M. J., Foster, K. L., Jungwirth, P., Tobias, D. J., Gerber, R. B., Dabdub, D., and FinlaysonPitts, B. J.: Experiments and simulations of ion-enhanced interfacial chemistry on aqueous $\mathrm{NaCl}$ aerosols, Science, 288, 301-306, doi:10.1126/science.288.5464.301, 2000.

Kolb, C., Worsnop, D., Jayne, J., and Davidovits, P.: Comment on mathematical models of the uptake of $\mathrm{ClONO}_{2}$ and other gases by atmospheric aerosols, J. Aerosol Sci., 29, 893-897, doi:10.1016/S0021-8502(97)10022-2, 1998.

Kolb, C. E., Cox, R. A., Abbatt, J. P. D., Ammann, M., Davis, E. J., Donaldson, D. J., Garrett, B. C., George, C., Griffiths, P. T., Hanson, D. R., Kulmala, M., McFiggans, G., Pöschl, U., Riipinen, I., Rossi, M. J., Rudich, Y., Wagner, P. E., Winkler, P. M., Worsnop, D. R., and O' Dowd, C. D.: An overview of current issues in the uptake of atmospheric trace gases by aerosols and clouds, Atmos. Chem. Phys., 10, 10561-10605, doi:10.5194/acp-10-10561-2010, 2010.

Koop, T., Bookhold, J., Shiraiwa, M., and Pöschl, U.: Glass transition and phase state of organic compounds: dependency on molecular properties and implications for secondary organic aerosols in the atmosphere, Phys. Chem. Chem. Phys., 13, 19238-19255, doi:10.1039/C1CP22617G, 2011.

Laskin, A., Gaspar, D. J., Wang, W., Hunt, S. W., Cowin, J. P., Colson, S. D., and Finlayson-Pitts, B. J.: Reactions at interfaces as a source of sulfate formation in sea-salt particles, Science, 301, 340-344, doi:10.1126/science.1085374, 2003.

Lee, A. K. and Chan, C. K.: Single particle Raman spectroscopy for investigating atmospheric heterogeneous reactions of organic aerosols, Atmos. Environ., 41, 4611-4621, doi:10.1016/j.atmosenv.2007.03.040, 2007. 
Lee, G., Lee, B., Kim, J., and Cho, K.: Ozone adsorption on graphene: ab initio study and experimental validation, J. Phys. Chem. C., 113, 14225-14229, doi:10.1021/jp904321n, 2009.

Mahowald, N., Ward, D. S., Kloster, S., Flanner, M. G., Heald, C. L., Heavens, N. G., Hess, P. G., Lamarque, J.-F., and Chuang, P. Y.: Aerosol Impacts on Climate and Biogeochemistry, Annu Rev. Environ. Resour., 36, 45-74, doi:10.1146/annurevenviron-042009-094507, 2011.

Maranzana, A., Serra, G., Giordana, A., Tonachini, G., Barco, G., and Causà, M.: Ozone interaction with polycyclic aromatic hydrocarbons and soot in atmospheric processes: theoretical density functional study by molecular and periodic methodologies, J. Phys. Chem. A, 109, 10929-10939, doi:10.1021/jp053672q, 2005.

Martien, P. T. and Harley, R. A.: Adjoint sensitivity analysis for a three-dimensional photochemical model: application to Southern California, Environ. Sci. Technol., 40, 4200-4210, doi:10.1021/es051026z, 2006.

Massman, W.: A review of the molecular diffusivities of $\mathrm{H}_{2} \mathrm{O}, \mathrm{CO}_{2}$, $\mathrm{CH}_{4}, \mathrm{CO}, \mathrm{O}_{3}, \mathrm{SO}_{2}, \mathrm{NH}_{3}, \mathrm{~N}_{2} \mathrm{O}, \mathrm{NO}$, and $\mathrm{NO}_{2}$ in air, $\mathrm{O}_{2}$ and $\mathrm{N}_{2}$ near STP, Atmos. Environ., 32, 1111-1127, doi:10.1016/S13522310(97)00391-9, 1998

McConnell, R., Berhane, K., Gilliland, F., London, S. J., Islam, T., Gauderman, W. J., Avol, E., Margolis, H. G., and Peters, J. M.: Asthma in exercising children exposed to ozone: a cohort study, Lancet, 359, 386-391, doi:10.1016/S01406736(02)07597-9, 2002.

Mikhailov, E., Vlasenko, S., Martin, S. T., Koop, T., and Pöschl, U.: Amorphous and crystalline aerosol particles interacting with water vapor: conceptual framework and experimental evidence for restructuring, phase transitions and kinetic limitations, Atmos. Chem. Phys., 9, 9491-9522, doi:10.5194/acp-9-9491-2009, 2009.

Morris, J. R., Behr, P., Antman, M. D., Ringeisen, B. R., Splan, J., and Nathanson, G. M.: Molecular beam scattering from supercooled sulfuric acid: collisions of $\mathrm{HCl}, \mathrm{HBr}$, and $\mathrm{HNO}_{3}$ with 70 wt $\mathrm{D}_{2} \mathrm{SO}_{4}$, J. Phys. Chem. A, 104, 6738-6751, doi:10.1021/jp000105o, 2000.

Morris, M.: Factorial sampling plans for preliminary computational experiments, Technometrics, 33, 161-174, available at: http://www.jstor.org/stable/10.2307/1269043, 1991.

Nel, A.: Air pollution-related illness: effects of particles, Science, 308, 804-806, doi:10.1126/science.1108752, 2005.

Oldridge, N. W. and Abbatt, J. P. D.: Formation of gas-phase bromine from interaction of ozone with frozen and liquid $\mathrm{NaCl} / \mathrm{NaBr}$ solutions: quantitative separation of surficial chemistry from bulk-phase reaction, J. Phys. Chem. A, 115, 25902598, doi:10.1021/jp200074u, 2011.

Pfrang, C., Shiraiwa, M., and Pöschl, U.: Coupling aerosol surface and bulk chemistry with a kinetic double layer model (K2-SUB): oxidation of oleic acid by ozone, Atmos. Chem. Phys., 10, 45374557, doi:10.5194/acp-10-4537-2010, 2010.

Pfrang, C., Shiraiwa, M., and Pöschl, U.: Chemical ageing and transformation of diffusivity in semi-solid multi-component organic aerosol particles, Atmos. Chem. Phys., 11, 7343-7354, doi:10.5194/acp-11-7343-2011, 2011

Pöschl, U.: Atmospheric Aerosols: Composition, Transformation, Climate and Health Effects, Angew. Chem. Int. Ed., 44, 7520 7540, doi:10.1002/anie.200501122, 2005.
Pöschl, U., Rudich, Y., and Ammann, M.: Kinetic model framework for aerosol and cloud surface chemistry and gas-particle interactions - Part 1: General equations, parameters, and terminology, Atmos. Chem. Phys., 7, 5989-6023, doi:10.5194/acp-75989-2007, 2007.

Ravishankara, A. R.: Heterogeneous and multiphase chemistry in the troposphere, Science, 276, 1058-1065, doi:10.1126/science.276.5315.1058, 1997.

Ravishankara, A. R. and Longfellow, C. A.: Reactions on tropospheric condensed matter Plenary Lecture, Phys. Chem. Chem. Phys., 1, 5433-5441, doi:10.1039/A905660B, 1999.

Renbaum, L. H. and Smith, G. D.: Artifacts in measuring aerosol uptake kinetics: the roles of time, concentration and adsorption, Atmos. Chem. Phys., 11, 6881-6893, doi:10.5194/acp-11-68812011, 2011.

Rouvière, A. and Ammann, M.: The effect of fatty acid surfactants on the uptake of ozone to aqueous halogenide particles, Atmos. Chem. Phys., 10, 11489-11500, doi:10.5194/acp-1011489-2010, 2010.

Rouvière, A., Sosedova, Y., and Ammann, M.: Uptake of ozone to deliquesced $\mathrm{KI}$ and mixed $\mathrm{KI} / \mathrm{NaCl}$ aerosol particles, J. Phys. Chem. A, 114, 7085-7093, doi:10.1021/jp103257d, 2010.

Saltelli, A., Ratto, M., Andres, T., Campolongo, F., Cariboni, J., Gatelli, D., Saisana, M., and Tarantola, S.: Global sensitivity analysis: the primer, Wiley Online Library, doi:10.1002/9780470725184.fmatter, last access: 15 November 2011, 2008.

Schwartz, S.: Mass-Transport Considerations Pertinent to Aqueous Phase Reactions of Gases in Liquid-Water Clouds, NATO ASI Series, vol. G6, Springer Verlag, Heidelberg, Germany, chemistry of multiphase atmospheric systems, 1986.

Schwartz, S. and Freiberg, J. E.: Mass-transport limitation to the rate of reaction of gases in liquid droplets: application to oxidation of $\mathrm{SO}_{2}$ in aqueous solutions, Atmos. Environ., 15, 11291144, doi:10.1016/0004-6981(81)90303-6, 1981.

Seinfeld, J. H. and Pandis, S. N.: Atmospheric Chemistry and Physics: From Air Pollution to Climate Change, Wiley, New York, 2006.

Shaka', H., Robertson, W. H., and Finlayson-Pitts, B. J.: A new approach to studying aqueous reactions using diffuse reflectance infrared Fourier transform spectrometry: application to the uptake and oxidation of $\mathrm{SO} 2$ on $\mathrm{OH}$-processed model sea salt aerosol, Phys. Chem. Chem. Phys., 9, 1980-1990, doi:10.1039/B612624C, 2007.

Shiraiwa, M., Garland, R. M., and Pöschl, U.: Kinetic double-layer model of aerosol surface chemistry and gas-particle interactions (K2-SURF): Degradation of polycyclic aromatic hydrocarbons exposed to $\mathrm{O}_{3}, \mathrm{NO}_{2}, \mathrm{H}_{2} \mathrm{O}, \mathrm{OH}$ and $\mathrm{NO}_{3}$, Atmos. Chem. Phys., 9, 9571-9586, doi:10.5194/acp-9-9571-2009, 2009.

Shiraiwa, M., Pfrang, C., and Pöschl, U.: Kinetic multi-layer model of aerosol surface and bulk chemistry (KM-SUB): the influence of interfacial transport and bulk diffusion on the oxidation of oleic acid by ozone, Atmos. Chem. Phys., 10, 3673-3691, doi:10.5194/acp-10-3673-2010, 2010.

Shiraiwa, M., Ammann, M., Koop, T., and Pöschl, U.: Gas uptake and chemical aging of semisolid organic aerosol particles, P. Natl. Acad. Sci. USA, 108, 11003-11008, doi:10.1073/pnas.1103045108, 2011a. 
Shiraiwa, M., Sosedova, Y., Rouvière, A., Yang, H., Zhang, Y., Abbatt, J. P. D., Ammann, M., and Pöschl, U.: The role of long-lived reactive oxygen intermediates in the reaction of ozone with aerosol particles, Nat. Chem., 3, 291-295, doi:10.1038/nchem.988, 2011b.

Shiraiwa, M., Pfrang, C., Koop, T., and Pöschl, U.: Kinetic multilayer model of gas-particle interactions in aerosols and clouds (KM-GAP): linking condensation, evaporation and chemical reactions of organics, oxidants and water, Atmos. Chem. Phys., 12, 2777-2794, doi:10.5194/acp-12-2777-2012, 2012a.

Shiraiwa, M., Pöschl, U., and Knopf, D. A.: Multiphase chemical kinetics of $\mathrm{NO}_{3}$ radicals reacting with organic aerosol components from biomass burning, Environ. Sci. Technol., 46, 66306636, doi:10.1021/es300677a, 2012b.

Shiraiwa, M., Selzle, K., Yang, H., Sosedova, Y., Ammann, M., and Pöschl, U.: Multiphase chemical kinetics of the nitration of aerosolized protein by ozone and nitrogen dioxide, Environ. Sci. Technol., 46, 6672-6680, doi:10.1021/es300871b, 2012c.

Shiraiwa, M., Selzle, K. and Pöschl, U.: Hazardous components and health effects of atmospheric aerosol particles: reactive oxygen species, soot, polycyclic aromatic compounds and allergenic proteins., Free Radical Res., 46(8), 927-939, doi:10.3109/10715762.2012.663084, 2012d.

Smith, G. D., Woods, E., DeForest, C. L., Baer, T., and Miller, R. E.: Reactive uptake of ozone by oleic acid aerosol particles: application of single-particle mass spectrometry to heterogeneous reaction kinetics, J. Phys. Chem. A, 106, 8085-8095, doi:10.1021/jp020527t, 2002.

Smith, G. D., Woods, E., Baer, T., and Miller, R. E.: Aerosol uptake described by numerical solution of the diffusion-reaction equations in the particle, J. Phys. Chem. A, 107, 9582-9587, doi:10.1021/jp021843a, 2003.

Stevens, B. and Feingold, G.: Untangling aerosol effects on clouds and precipitation in a buffered system., Nature, 461, 607-613, doi:10.1038/nature08281, 2009.

Streets, D. G., Bond, T. C., Lee, T., and Jang, C.: On the future of carbonaceous aerosol emissions, J. Geophys. Res., 109, D24212, doi:10.1029/2004JD004902, 2004.

Tong, H.-J., Reid, J. P., Bones, D. L., Luo, B. P., and Krieger, U. K.: Measurements of the timescales for the mass transfer of water in glassy aerosol at low relative humidity and ambient temperature, Atmos. Chem. Phys., 11, 4739-4754, doi:10.5194/acp-11-47392011, 2011.
Virtanen, A., Joutsensaari, J., Koop, T., Kannosto, J., Yli-Pirila, P., Leskinen, J., Makela, J. M., Holopainen, J. K., Pöschl, U., Kulmala, M., Worsnop, D. R., and Laaksonen, A.: An amorphous solid state of biogenic secondary organic aerosol particles, Nature, 467, 824-827, doi:10.1038/nature09455, 2010.

Worsnop, D. R., Morris, J. W., Shi, Q., Davidovits, P., and Kolb, C. E.: A chemical kinetic model for reactive transformations of aerosol particles, Geophys. Res. Lett., 29, 1996, doi:10.1029/2002GL015542, 2002.

Yu, H., Kaufman, Y. J., Chin, M., Feingold, G., Remer, L. A., Anderson, T. L., Balkanski, Y., Bellouin, N., Boucher, O., Christopher, S., DeCola, P., Kahn, R., Koch, D., Loeb, N., Reddy, M. S., Schulz, M., Takemura, T., and Zhou, M.: A review of measurement-based assessments of the aerosol direct radiative effect and forcing, Atmos. Chem. Phys., 6, 613-666, doi:10.5194/acp-6-613-2006, 2006.

Zahardis, J. and Petrucci, G. A.: The oleic acid-ozone heterogeneous reaction system: products, kinetics, secondary chemistry, and atmospheric implications of a model system - a review, Atmos. Chem. Phys., 7, 1237-1274, doi:10.5194/acp-7-1237-2007, 2007.

Ziemann, P. J.: Aerosol products, mechanisms, and kinetics of heterogeneous reactions of ozone with oleic acid in pure and mixed particles, Faraday Discuss., 130, 469-490, doi:10.1039/B417502F, 2005.

Ziemann, P. J. and Atkinson, R.: Kinetics, products, and mechanisms of secondary organic aerosol formation, Chem. Soc. Rev., 41, 6582-6605, doi:10.1039/c2cs35122f, 2012.

Zobrist, B., Marcolli, C., Pedernera, D. A., and Koop, T.: Do atmospheric aerosols form glasses?, Atmos. Chem. Phys., 8, 52215244, doi:10.5194/acp-8-5221-2008, 2008.

Zobrist, B., Soonsin, V., Luo, B. P., Krieger, U. K., Marcolli, C., Peter, T., and Koop, T.: Ultra-slow water diffusion in aqueous sucrose glasses, Phys. Chem. Chem. Phys., 13, 3514-3526, doi:10.1039/C0CP01273D, 2011. 